\title{
Sulfamide antifolates inhibiting thymidylate synthase: synthesis, enzyme inhibition and cytotoxicity ${ }^{\star \otimes}$
}

Krzysztof Pawełczak ${ }^{1 凶}$, Maciej Makowski ${ }^{1}$, Michał Kempny ${ }^{1}$, Jolanta M. Dzik² Barbara Gołos ${ }^{2}$, Wojciech Rode ${ }^{2}$ and Barbara Rzeszotarska ${ }^{1}$

${ }^{1}$ Institute of Chemistry, University of Opole, Opole, Poland; ${ }^{2}$ Nencki Institute of Experimental Biology, Warszawa, Poland

Received: 01 June, 2002; accepted: 05 June, 2002

Key words: antifolates, thymidylate synthase inhibitors, $p$-aminobenzenesulfonic acid, antifolate analogues

\begin{abstract}
Synthesis and biological evaluation are described of seven new analogues (3-9) of two potent thymidylate synthase inhibitors, 10-propargyl-5,8-dideazafolate (1) and its 2-methyl-2-deamino congener ICI 198583 (2). While the new compunds 3 and 4 were analogues of 1 and 2 , respectively, containing a $p$-aminobenzenesulfonyl residue in place of the $p$-aminobenzoic acid residue, the remaining 5 new compounds were analogues of 4 with the L-glutamic acid residue replaced by glycine (5), L-valine (6), L-alanine (7), L-phenylglycine (8) or L-norvaline (9). The new analogues were tested as inhibitors of thymidylate synthases isolated from tumour (Ehrlich carcinoma), parasite (Hymenolepis diminuta) and normal tissue (regenerating rat liver) and found to be weaker inhibitors than the parent 10-propargyl-5,8-dideazafolic acid. Selected new analogues, tested as inhibitors of growth of mouse leukemia $L 5178 Y$ cells, were less potent than the parent 10-propargyl-5,8-dideazafolic acid. Substitution of the glutamyl residue in compound 4 with L-norvaline (9) resulted in only a 5 -fold stronger thymidylate synthase inhibitor, but a 40-fold weaker cell growth inhibitor.
\end{abstract}

Thymidylate synthase (EC 2.1.1.45) catalyzes the $\mathrm{C}(5)$ methylation of 2 '-deoxyuridylate (dUMP) in a concerted transfer and reduction of the one-carbon group (at the alde- hyde oxidation level) of $N^{5},{ }^{10}$-methylenetetrahydrofolate, and with concomitant production of dihydrofolate and thymidylate. The in vivo folate cofactor and the product of the

\footnotetext{
${ }^{\star}$ Preliminary reports were presented at the 10th Int. Symp. "Chemistry and Biology of Pteridines and Folates", Orange Beach, Alabama, 1993; at the $4^{\text {th }}$ Int. Symp. "Molecular Aspects of Chemotheraphy", Gdańsk, 1993; and at the 6th Int. Cong. of "Anticancer Treatment”, Paris 1996.

${ }^{*}$ Supported by the State Committee for Scientific Research (KBN, Poland, grant No. 6625492 03).

${ }^{凶}$ Corresponding author: Krzysztof Pawełczak, Institute of Chemistry, University of Opole, 48 Oleska St., 45-052 Opole, Poland; phone: (48 77) 4545841 ext. 2356; fax: (48 77) 441 0740: e-mail: pawel@uni.opole.pl
}

Abbreviations: DMA, dimethylacetamide; DMF, dimethylformamide; LSIMS, liquid secondary ion spectroscopy; mp, melting point. 
reaction are usually in their $\gamma$-oligoglutamate forms, preventing transport through the cell membrane (Carreras \& Santi, 1995). The sequential addition of L-glutamic acid residues in a $\gamma$-carboxyl peptide linkage to folate cofactors (and their analogues) is catalyzed by an ATP $\cdot \mathrm{Mg}^{2+}$-dependent enzyme, folylpolyglutamate synthetase (EC 6.3.2.17) (Synold et al., 1996). As the sole de novo source of thymidylate synthesis in cells, it is a target in anticancer, antiviral, antifungal and antiprotozoan chemotherapy (Heidelberger et al., 1983; Rathod, 1997; Georgopapadakou \& Walsh, 1996; Takemura \& Jackman, 1997).

The cofactor analogues, 10-propargyl-5,8-dideazafolic acid 1 (Fig. 1) and 2-deamino-2-methyl- $N^{10}$-propargyl-5,8-dideazafolic acid $\mathbf{2}$ (ICI 198583; Fig. 1) are potent inhibitors of



\begin{tabular}{|c|c|c|c|}
\hline \multicolumn{3}{|c|}{ Compound } & \multirow[b]{2}{*}{$\mathrm{R}^{\prime}$} \\
\hline Abbreviation (No.) & $\mathrm{R}$ & $\mathrm{X}$ & \\
\hline pddPteGlu (1) & $\mathrm{NH}_{2}$ & $\mathrm{CO}$ & Glu \\
\hline $\mathrm{CH}_{3}$ pddPteGlu; ICI 198583 (2) & $\mathrm{CH}_{3}$ & $\mathrm{CO}$ & Glu \\
\hline pddPteSO ${ }_{2}$ Glu (3) & $\mathrm{NH}_{2}$ & $\mathrm{SO}_{2}$ & Glu \\
\hline $\mathrm{CH}_{3}$ pddPteSO$_{2} \mathrm{Glu}(\mathbf{4})$ & $\mathrm{CH}_{3}$ & $\mathrm{SO}_{2}$ & Glu \\
\hline $\mathrm{CH}_{3}$ pddPteSO ${ }_{2}$ Gly (5) & $\mathrm{CH}_{3}$ & $\mathrm{SO}_{2}$ & Gly \\
\hline $\mathrm{CH}_{3} \mathrm{pddPteSO}_{2} \mathrm{Val}(\mathbf{6})$ & $\mathrm{CH}_{3}$ & $\mathrm{SO}_{2}$ & Val \\
\hline $\mathrm{CH}_{3}$ pddPteSO ${ }_{2} \mathrm{Ala}(7)$ & $\mathrm{CH}_{3}$ & $\mathrm{SO}_{2}$ & Ala \\
\hline $\mathrm{CH}_{3}$ pddPteSO ${ }_{2}$ PhGly (8) & $\mathrm{CH}_{3}$ & $\mathrm{SO}_{2}$ & PhGly \\
\hline $\mathrm{CH}_{3}$ pddPteSO ${ }_{2} \mathrm{NVal}$ (9) & $\mathrm{CH}_{3}$ & $\mathrm{SO}_{2}$ & Nva \\
\hline
\end{tabular}

Figure 1. Structures of 10-propargyl-5,8-dideazafolic acid (1), 2-deamino-2-methyl- $N^{10}$-propargyl5,8-dideazafolic acid (2; ICI 198583) and their analogues.

thymidylate synthase, their cytotoxic activity being strongly dependent on intracellular me- tabolism by folylpolyglutamate synthetase to polyglutamated derivatives, well retained within cells and more potent as inhibitors of the enzyme (Rosowsky, 1992). As dependence of antifolate cytotoxicity on polyglutamation may display some disadvantages, such as (i) lack of activity in tumours expressing a low level of, or an altered, folylpolyglutamate synthetase, (ii) prolonged normal tissue toxicities caused by polyglutamate retention or (iii) lack of activity due to an increased activity of $\gamma$-glutamyl hydrolases, new non-polyglutamatable folate-based thymidylate synthase inhibitors are being sought (Takemura \& Jackman, 1997).

To learn more about the effect of the $p$-aminobenzoylglutamate residue of $N^{5,10}$-methylenetetrahydrofolate analogues on interaction with thymidylate synthase, and seeking non-polyglutamatable inhibitors of the enzyme, seven new compounds, ( $N$-[ $p$-[ $N$-(3,4-dihydro-2-amino-4-oxo-6-quinazolinyl)methyl]$N$-prop-2-ynylamino]benzenesulfonyl]-L-glutamic acid (3), $N$-[ $p$-[ $N$-(3,4-dihydro-2-methyl-4-oxo-6-quinazolinyl)methyl]- $N$-prop-2-ynylamino]benzenesulfonyl]-L-glutamic acid (4), $\gamma$-glycine (5), -L-valine (6), -L-alanine (7), -L-phenylglycine (8) and -L-norvaline (9)), have been synthesized and tested as inhibitors of thymidylate synthase and tumour cell growth. The compounds $\mathbf{3}$ and $\mathbf{4}$ are analogues of the two thymidylate synthase inhibitors $\mathbf{1}$ and $\mathbf{2}$, respectively, in which a $p$-aminobenzenesulfonyl residue replaces the $p$-aminobenzoic acid. The compounds 5-9, analogues of 4 , have been additionally modified by replacing the L-glutamic acid residue with glycine (5), L-valine (6), L-alanine (7), L-phenylglycine (8) or L-norvaline (9).

\section{MATERIALS AND METHODS}

\section{Chemistry: General}

2-Amino-6-bromomethyl-3,4-dihydro-4-oxoquinazoline hydrobromide (Calvert et al., 
1980), 6-bromomethyl-3,4-dihydro-2-methyl-4oxyquinazoline (Marsham et al., 1990) and appropriate amino acid tert-butyl ester hydrochlorides (Roeske, 1963) were prepared as described. The $p$-nitrobenzenesulfonyl chloride was from Merck (\# 820885) and propargyl bromide from Fluka (\# 81830). Tetrahydrofuran, dioxane, diethyl ether and triethylamine were distilled over sodium and stored over sodium wire. Dimethylformamide (DMF) was azeotropically distilled and stored, like dimethylacetamide (DMA), over activated $\left(250^{\circ} \mathrm{C}\right) 4 \AA$ molecular sieves. The hydrogenolysis catalyst was $10 \% \mathrm{Pd} / \mathrm{C}$ used at $20 \%$ of the substrate weight. Reactions were monitored, and homogeneity of products checked, by TLC on silica gel 60 (Merck, \# 5553) in the following systems: (A) $8 \% \mathrm{CH}_{3} \mathrm{OH}$ in $\mathrm{CHCl}_{3}$; (B) $20 \%$ $\mathrm{CH}_{3} \mathrm{OH}$ in $\mathrm{CHCl}_{3}$; (C) $35 \%$ acetone in $\mathrm{CHCl}_{3}$; (D) $5 \%$ acetone in $\mathrm{CHCl}_{3}$ and (E) acetone. Spots were visualised with the chlorine-tolidine reagent. Fully protected compounds (16-34) were purified by low-pressure column chromatography on silica gel 60 (Merck, \# 7736). Melting points (uncorrected) were determined on a Boëtius heating block. ${ }^{1} \mathrm{H}$ NMR spectra were recorded in $\left[\left(\mathrm{CH}_{3}\right)_{2} \mathrm{SO}-\mathrm{d}_{6}\right]$ on a Brucker WM 250 spectrometer. Chemical shifts are expressed as $\delta$ (ppm), and peak multiplicities are designated as follows: s, singlet; $\mathrm{d}$, doublet; dd, doublet of doublets; t, triplet; br s, broad singlet; $\mathrm{m}$, multiplet. LSIMS mass spectra were obtained on an AMD 604 Intectra $\mathrm{GmbH}$ mass spectrometer.

$\mathrm{N}$-(p-Nitrobenzenesulfonyl)amino acid tert-butyl esters (10-15). General procedure. To a stirred solution of an appropriate amino acid tert-butyl ester hydrochloride (1 $\mathrm{mM}$ ) and $p$-nitrobenzenesulfonyl chloride (1 $\mathrm{mM})$ in tetrahydrofuran $(2 \mathrm{ml})$ cooled to $-10^{\circ} \mathrm{C}, \mathrm{N}$-methylmorpholine (2 $\left.\mathrm{mmol}\right)$ was added dropwise during $10 \mathrm{~min}$. Stirring was continued at $-10^{\circ} \mathrm{C}$ for $10 \mathrm{~min}$ and at $20^{\circ} \mathrm{C}$ for $1 \mathrm{~h}$, whereupon TLC (system A) showed the absence of starting material. $N$-Methylmorpholine hydrochloride was filtered off and the filtrate evaporated to dryness. The resulting residue was crystallised from diethyl ether/hexane. Yields and melting points of the products 10-15, chromatographically homogeneous in system $\mathrm{A}$, are given in Table 1.

Table 1. $N$-( $p$-Nitrobenzenesulfonyl)amino acid tert-butyl esters (10-15) and $N$-(p-aminobenzenesulfonyl)amino acid tert-butyl esters (16-21)

\begin{tabular}{|c|c|c|c|c|c|c|c|}
\hline \multirow{2}{*}{$\begin{array}{c}\text { Compd. } \\
\text { No. }\end{array}$} & \multirow{2}{*}{$\begin{array}{c}\text { Scale } \\
\mathrm{mM}\end{array}$} & \multirow{2}{*}{$\begin{array}{c}\text { Yield } \\
\%\end{array}$} & \multirow{2}{*}{$\begin{array}{l}\mathrm{mp} \\
{ }^{\circ} \mathrm{C}\end{array}$} & \multirow[t]{2}{*}{ Formula } & \multicolumn{3}{|c|}{ Anal. Calcd (Found) } \\
\hline & & & & & $\mathrm{C}$ & $\mathrm{H}$ & $\mathrm{N}$ \\
\hline 10 & 15 & 92 & $72-73$ & $\mathrm{C}_{19} \mathrm{H}_{28} \mathrm{~N}_{2} \mathrm{O}_{8} \mathrm{~S}$ & $\begin{array}{c}51.34 \\
(51.12)\end{array}$ & $\begin{array}{l}6.35 \\
(6.31)\end{array}$ & $\begin{array}{l}6.30 \\
(6.24)\end{array}$ \\
\hline 11 & 10 & 94 & $138-140$ & $\mathrm{C}_{12} \mathrm{H}_{16} \mathrm{~N}_{2} \mathrm{O}_{6} \mathrm{~S}$ & $\begin{array}{l}45.56 \\
(45.21)\end{array}$ & $\begin{array}{l}5.10 \\
(5.02)\end{array}$ & $\begin{array}{l}8.86 \\
(8.58)\end{array}$ \\
\hline 12 & 10 & 93 & $91-93$ & $\mathrm{C}_{15} \mathrm{H}_{22} \mathrm{~N}_{2} \mathrm{O}_{6} \mathrm{~S}$ & $\begin{array}{c}50.27 \\
(50.34)\end{array}$ & $\begin{array}{l}6.19 \\
(6.28)\end{array}$ & $\begin{array}{l}7.82 \\
(7.80)\end{array}$ \\
\hline 13 & 10 & 95 & $90-92$ & $\mathrm{C}_{13} \mathrm{H}_{18} \mathrm{~N}_{2} \mathrm{O}_{6} \mathrm{~S}$ & $\begin{array}{l}47.26 \\
(47.12)\end{array}$ & $\begin{array}{l}5.49 \\
(5.22)\end{array}$ & $\begin{array}{l}8.48 \\
(8.39)\end{array}$ \\
\hline 14 & 15 & 93 & $138-140$ & $\mathrm{C}_{18} \mathrm{H}_{20} \mathrm{~N}_{2} \mathrm{O}_{6} \mathrm{~S}$ & $\begin{array}{c}55.09 \\
(55.06)\end{array}$ & $\begin{array}{l}5.14 \\
(5.12)\end{array}$ & $\begin{array}{l}7.14 \\
(7.17)\end{array}$ \\
\hline 15 & 10 & 96 & $100-102$ & $\mathrm{C}_{15} \mathrm{H}_{22} \mathrm{~N}_{2} \mathrm{O}_{6} \mathrm{~S}$ & $\begin{array}{c}50.27 \\
(50.34)\end{array}$ & $\begin{array}{l}6.19 \\
(6.22)\end{array}$ & $\begin{array}{l}7.82 \\
(7.87)\end{array}$ \\
\hline 16 & 7 & 98 & $110-111$ & $\mathrm{C}_{19} \mathrm{H}_{30} \mathrm{~N}_{2} \mathrm{O}_{6} \mathrm{~S}$ & $\begin{array}{c}55.05 \\
(55.25)\end{array}$ & $\begin{array}{l}7.29 \\
(7.21)\end{array}$ & $\begin{array}{l}6.76 \\
(6.54)\end{array}$ \\
\hline 17 & 9 & 96 & $141-143$ & $\mathrm{C}_{12} \mathrm{H}_{18} \mathrm{~N}_{2} \mathrm{O}_{4} \mathrm{~S}$ & $\begin{array}{c}50.33 \\
(50.42)\end{array}$ & $\begin{array}{l}6.34 \\
(6.27)\end{array}$ & $\begin{array}{l}9.78 \\
(9.54)\end{array}$ \\
\hline 18 & 10 & 97 & $171-172$ & $\mathrm{C}_{15} \mathrm{H}_{24} \mathrm{~N}_{2} \mathrm{O}_{4} \mathrm{~S}$ & $\begin{array}{l}54.86 \\
(55.02)\end{array}$ & $\begin{array}{l}7.37 \\
(7.21)\end{array}$ & $\begin{array}{l}8.53 \\
(8.33)\end{array}$ \\
\hline 19 & 9 & 95 & $141-144$ & $\mathrm{C}_{13} \mathrm{H}_{20} \mathrm{~N}_{2} \mathrm{O}_{4} \mathrm{~S}$ & $\begin{array}{c}51.98 \\
(51.78)\end{array}$ & $\begin{array}{l}6.71 \\
(6.88)\end{array}$ & $\begin{array}{l}9.33 \\
(9.43)\end{array}$ \\
\hline 20 & 12 & 97 & $162-164$ & $\mathrm{C}_{18} \mathrm{H}_{22} \mathrm{~N}_{2} \mathrm{O}_{4} \mathrm{~S}$ & $\begin{array}{c}59.65 \\
(59.51)\end{array}$ & $\begin{array}{l}6.12 \\
(6.18)\end{array}$ & $\begin{array}{l}7.73 \\
(7.84)\end{array}$ \\
\hline 21 & 9 & 85 & $157-160$ & $\mathrm{C}_{15} \mathrm{H}_{24} \mathrm{~N}_{2} \mathrm{O}_{4} \mathrm{~S}$ & $\begin{array}{c}54.86 \\
(54.62)\end{array}$ & $\begin{array}{l}7.37 \\
(7.44)\end{array}$ & $\begin{array}{l}8.53 \\
(8.67)\end{array}$ \\
\hline
\end{tabular}


$\mathrm{N}$-(p-Aminobenzenesulfonyl)amino acid tert-butyl esters (16-21). General procedure. To a solution of an $N$-( $p$-nitrobenzenesulfonyl)amino acid tert-butyl ester ( $1 \mathrm{mM})$ in $\mathrm{EtOH}(10 \mathrm{ml}), \mathrm{Pd} / \mathrm{C}$ was added and the suspension stirred under hydrogen until TLC (system A) showed absence of starting material (from $45 \mathrm{~min}$ to $2 \mathrm{~h}$ ). The catalyst was filtered off and the filtrate evaporated to dryness. The resulting white crystalline powders were used in the next reactions. Yield and analytical data of the products 16-21, chromatographically homogeneous in system $\mathrm{A}$, are given in Table 1.

Di-tert-butyl N-/p-(prop-2-ynylamino)benzenesulfonyl]-L-glutamate (22). A mixture of 16 (2.86 g, $6.6 \mathrm{mM}), \mathrm{CaCO}_{3}(0.80 \mathrm{~g}, 8 \mathrm{mM})$ and propargyl bromide $(0.64 \mathrm{ml}, 8 \mathrm{mM})$ in DMF $(13 \mathrm{ml})$ was stirred in the dark at $20^{\circ} \mathrm{C}$ for $72 \mathrm{~h}$. The mixture was poured into chloroform $(200 \mathrm{ml})$, salts filtered off, the chloroform evaporated and ethyl acetate $(200 \mathrm{ml})$ added. The organic phase was washed with $\mathrm{H}_{2} \mathrm{O}(2 \times 300 \mathrm{ml})$ and brine $(200 \mathrm{ml})$, dried over $\mathrm{Na}_{2} \mathrm{SO}_{4}$ and the solvent then removed in vacuo. The resulting oil, dissolved in chloroform $(20 \mathrm{ml})$, was purified on a column [gel $(60 \mathrm{~g}) ; 5 \mathrm{~cm}$ i.d. $\times 8 \mathrm{~cm} \mathrm{~L}$, by elution with chloroform (50 $\mathrm{ml}), 1 \%$ acetone in chloroform $(50 \mathrm{ml})$ and $2 \%$ acetone in chloroform $(250 \mathrm{ml})$ to give an oily residue. This was crystallized from chloroform/hexane; $1.64 \mathrm{~g}$ (54.6\%); mp $127-128^{\circ} \mathrm{C}$; ${ }^{1} \mathrm{H}$ NMR, $\delta: 1.24,1.38(2 \mathrm{~s}, 18 \mathrm{H}$, $\left.2^{\mathrm{t}} \mathrm{Bu}\right), 1.72\left(\mathrm{~m}, 2 \mathrm{H}\right.$, Glu $\left.{ }^{\beta} \mathrm{CH}_{2}\right), 2.22(\mathrm{~m}, 2 \mathrm{H}$, Glu, ${ }^{\gamma} \mathrm{CH}_{2}$ ), $3.09(\mathrm{t}, J=2.4 \mathrm{~Hz}, 1 \mathrm{H}, \mathrm{C} \equiv \mathrm{CH})$, $3.61\left(\mathrm{~m}, 1 \mathrm{H}, \mathrm{Glu}{ }^{\alpha} \mathrm{CH}\right), 3.92(\mathrm{dd}, J=6.0 \mathrm{~Hz}$, $\left.2.4 \mathrm{~Hz}, 2 \mathrm{H}, \mathrm{CH}_{2} \mathrm{C} \equiv \mathrm{C}\right), 6.67(\mathrm{~d}, J=8.7 \mathrm{~Hz}$, $2 \mathrm{H}, \mathrm{Ph}: 3^{\prime}-\mathrm{H}$ and $\left.5^{\prime}-\mathrm{H}\right), 6.84(\mathrm{t}, J=5.9 \mathrm{~Hz}$, $\left.1 \mathrm{H}, \mathrm{CH}_{2}-\mathrm{NH}\right), 7.46$ (d, $J=8.7 \mathrm{~Hz}, 2 \mathrm{H}, \mathrm{Ph}$ : $2^{\prime}-\mathrm{H}$ and $\left.6^{\prime}-\mathrm{H}\right), 7.73(\mathrm{~d}, J=9.0 \mathrm{~Hz}, 1 \mathrm{H}$, $\left.\mathrm{SO}_{2}-\mathrm{NH}\right)$. Anal. Calcd. for $\mathrm{C}_{22} \mathrm{H}_{32} \mathrm{~N}_{2} \mathrm{O}_{6} \mathrm{~S}$ : C, 58.39; H, 7.13; N, 6.19. Found: C, 58.47; H, 7.02; N, 5.26.

tert-Butyl N-[p-(prop-2-ynylamino)benzenesulfonyl]glycinate (23). A mixture of 17 (2.86 g, $10 \mathrm{mM}$ ), $\mathrm{CaCO}_{3}(1.13 \mathrm{~g}, 11 \mathrm{mM}$ ) and propargyl bromide $(0.86 \mathrm{ml}, 11 \mathrm{mM})$ in $\mathrm{DMF}$
(10 ml) was stirred at $27^{\circ} \mathrm{C}$ for $96 \mathrm{~h}$ and then worked up as for $\mathbf{2 2}$. The resulting oil, dissolved in $2 \%$ acetone in chloroform, was purified on a column [gel (110 g), $5 \mathrm{~cm}$ i.d. $\times 13$ $\mathrm{cm} \mathrm{L}$ ], using a gradient of $2.00-3.25 \%$ acetone in chloroform as eluent, to yield an oily residue. This was crystallized from chloroform/ diethyl ether/hexane (1:4:5); $2.36 \mathrm{~g}$ (73\%); $\mathrm{mp}$ 114-115 ${ }^{\circ} \mathrm{C}$; ${ }^{1} \mathrm{H}$ NMR, $\delta: 1.27\left(\mathrm{~s}, 9 \mathrm{H},{ }^{\mathrm{t}} \mathrm{Bu}\right), 3.24$ (t, $J=2.4 \mathrm{~Hz}, 1 \mathrm{H}, \mathrm{C} \equiv \mathrm{CH}), 3.47(\mathrm{~d}, J=5.2$ $\mathrm{Hz}, 2 \mathrm{H}, \mathrm{Gly} \mathrm{CH}_{2}$ ), 4.36 (dd, $J=6.0 \mathrm{~Hz}, 2.3$ $\left.\mathrm{Hz}, 2 \mathrm{H}, \mathrm{CH}_{2} \mathrm{C} \equiv \mathrm{C}\right) 6.78(\mathrm{t}, J=6.0 \mathrm{~Hz}, 1 \mathrm{H}$, $\left.\underline{\mathrm{NH}}-\mathrm{CH}_{2}-\mathrm{C} \equiv \mathrm{C}\right), 6.88(\mathrm{~d}, J=8.7 \mathrm{~Hz}, 2 \mathrm{H}, \mathrm{Ph}$ : $3^{\prime}-\mathrm{H}$ and $\left.5^{\prime}-\mathrm{H}\right), 7.57(\mathrm{~d}, J=8.7 \mathrm{~Hz}, \mathrm{Ph}: 2 \mathrm{H}$, $2^{\prime}-\mathrm{H}$ and $\left.6^{\prime}-\mathrm{H}\right), 7.71(\mathrm{t}, J=8.9 \mathrm{~Hz}, 1 \mathrm{H}$, $\left.\mathrm{SO}_{2}-\mathrm{NH}\right)$. Anal. Calcd. for $\mathrm{C}_{15} \mathrm{H}_{20} \mathrm{~N}_{2} \mathrm{O}_{4} \mathrm{~S}$ : C, 55.54; H, 6.21; N, 8.64. Found: C, 55.28; H, $6.37 ; \mathrm{N}, 8.76$.

tert-Butyl N-[p-(prop-2-ynylamino)benzenesulfonyl]-L-valinate (24). A mixture of 18 (3.12 g, $9.5 \mathrm{mM}), \mathrm{CaCO}_{3}(1.05 \mathrm{~g}, 10.5 \mathrm{mM})$ and propargyl bromide $(0.81 \mathrm{ml}, 10.5 \mathrm{mM})$ in DMF $(10 \mathrm{ml})$ was stirred at $20^{\circ} \mathrm{C}$ for $96 \mathrm{~h}$ and then worked up as for $\mathbf{2 2}$. The resulting oil, dissolved in chloroform, was purified on a column [gel $(110 \mathrm{~g}), 5 \mathrm{~cm}$ i.d. $\times 13.5 \mathrm{~cm} \mathrm{~L}$ ] using a gradient of $0.5-1.0 \%$ acetone in chloroform as eluent to give an oily residue. This was crystallized from chloroform/acetone/hexane (1:4:4); $2.5 \mathrm{~g}$ (73\%); mp $112.5-114^{\circ} \mathrm{C} ;{ }^{1} \mathrm{H}$ NMR, $\delta: 1.08\left(\mathrm{~d}, J=6.8 \mathrm{~Hz}, 6 \mathrm{H}, \mathrm{CH}\left(\mathrm{CH}_{3}\right)_{2}\right)$, $1.26\left(\mathrm{~s}, 9 \mathrm{H},{ }^{\mathrm{t}} \mathrm{Bu}\right), 2.32\left(\mathrm{~m}, 1 \mathrm{H}, \mathrm{Val}{ }^{\beta} \mathrm{CH}\right), 3.22$ (t, $J=2.4 \mathrm{~Hz}, 1 \mathrm{H}, \mathrm{C} \equiv \mathrm{CH}), 4.35(\mathrm{~d}, J=6.0$ $\left.\mathrm{Hz}, 2 \mathrm{H}, \mathrm{CH}_{2} \mathrm{C} \equiv \mathrm{C}\right), 4.62\left(\mathrm{~m}, 1 \mathrm{H}, \mathrm{Val}{ }^{\alpha} \mathrm{CH}\right)$, $6.56\left(\mathrm{t}, J=6.0 \mathrm{~Hz}, 1 \mathrm{H}, \underline{\mathrm{HN}}-\mathrm{CH}_{2}\right), 6.67(\mathrm{~d}$, $J=8.7 \mathrm{~Hz}, \mathrm{Ph}: 2 \mathrm{H}, 3^{\prime}-\mathrm{H}$ and $\left.5^{\prime}-\mathrm{H}\right), 7.46(\mathrm{~d}$, $J=8.7 \mathrm{~Hz}, 2 \mathrm{H}, \mathrm{Ph}: 2^{\prime}-\mathrm{H}$ and $\left.6^{\prime}-\mathrm{H}\right), 7.74(\mathrm{~d}$, $\left.J=8.8 \mathrm{~Hz}, 1 \mathrm{H}, \mathrm{SO}_{2}-\mathrm{NH}\right)$. Anal. Calcd. for $\mathrm{C}_{18} \mathrm{H}_{26} \mathrm{~N}_{2} \mathrm{O}_{4} \mathrm{~S}$ : C, 58.99; $\mathrm{H}, 7.15 ; \mathrm{N}, 7.64$. Found: C, 60.21; H, 7.02; N, 7.63.

tert-Butyl N-[p-(prop-2-ynylamino)benzenesulfonyl]-L-alaninate (25). A mixture of 19 (3.0 g, $10 \mathrm{mM}), \mathrm{CaCO}_{3}(1.10 \mathrm{~g}, 11 \mathrm{mM})$ and propargyl bromide $(0.86 \mathrm{ml}, 11 \mathrm{mM})$ in DMF $(10 \mathrm{ml})$ was stirred at $20^{\circ} \mathrm{C}$ for $100 \mathrm{~h}$ and then worked up as for $\mathbf{2 2}$. The resulting oil, dissolved in chloroform (10 ml), was purified on 
a column [gel (100 g), $5 \mathrm{~cm}$ i.d. $\times 12.5 \mathrm{~cm} \mathrm{~L}$, and eluted with chloroform (100 ml) and a gradient of $1-10 \%$ ethyl acetate in chloroform to give a light yellow oily residue. This slowly crystallized at low temperature to give $2.6 \mathrm{~g}$ (77\%); mp $117.5-119^{\circ} \mathrm{C} ;{ }^{1} \mathrm{H}$ NMR, $\delta: 1.12(\mathrm{~d}$, $\left.J=7.2 \mathrm{~Hz}, 3 \mathrm{H}, \mathrm{Ala} \mathrm{CH}_{3}\right), 1.21\left(\mathrm{~s}, 9 \mathrm{H},{ }^{\mathrm{t}} \mathrm{Bu}\right)$, $3.23(\mathrm{t}, J=2.4 \mathrm{~Hz}, 1 \mathrm{H}, \mathrm{C} \equiv \mathrm{CH}), 3.62(\mathrm{~m}, 1 \mathrm{H}$, $\left.\mathrm{Ala}{ }^{\alpha} \mathrm{CH}\right), 4.35\left(\mathrm{~d}, J=6.0 \mathrm{~Hz}, 2 \mathrm{H}, \mathrm{CH}_{2} \mathrm{C} \equiv \mathrm{C}\right)$, $6.71\left(\mathrm{t}, J=6.0 \mathrm{~Hz}, 1 \mathrm{H}, \underline{\mathrm{NH}}-\mathrm{CH}_{2}\right), 6.85(\mathrm{~d}$, $J=8.7 \mathrm{~Hz}, 2 \mathrm{H}, \mathrm{Ph}: 3^{\prime}-\mathrm{H}$ and $\left.5^{\prime}-\mathrm{H}\right), 7.57(\mathrm{~d}$, $J=8.7 \mathrm{~Hz}, 2 \mathrm{H}, \mathrm{Ph}: 2^{\prime}-\mathrm{H}$ and $\left.6^{\prime}-\mathrm{H}\right), 7.82(\mathrm{~d}$, $\left.J=8.5 \mathrm{~Hz}, 1 \mathrm{H}, \mathrm{SO}_{2}-\mathrm{NH}\right)$. Anal. Calcd. for $\mathrm{C}_{18} \mathrm{H}_{26} \mathrm{~N}_{2} \mathrm{O}_{4} \mathrm{~S}: \mathrm{C}, 56.78 ; \mathrm{H}, 6.55 ; \mathrm{N}, 8.28$. Found: C, 56.87; H, 6.45; N, 8.19.

tert-Butyl N-/p-(prop-2-ynylamino)benzenesulfonyl]-L-phenylglycinate (26). A mixture of 20 (3.62 g, $10 \mathrm{mM}$ ), $\mathrm{CaCO}_{3}(1.10 \mathrm{~g}, 11$ $\mathrm{mM})$ and propargyl bromide $(0.86 \mathrm{ml}, 11 \mathrm{mM})$ in DMF $(10 \mathrm{ml})$ was stirred at $20^{\circ} \mathrm{C}$ for $55 \mathrm{~h}$ and then worked up as for $\mathbf{2 2}$. The resulting oil, dissolved in a mixture of $\mathrm{CH}_{2} \mathrm{Cl}_{2}$ and $\mathrm{CHCl}_{3}$ (1:1) (10 ml), was purified on a column [gel (140 g), $5 \mathrm{~cm}$ i.d. $\times 14.5 \mathrm{~cm} \mathrm{~L}$ ), by elution with chloroform $(100 \mathrm{ml})$ and a gradient of $1.5-3.5 \%$ acetone in chloroform to give an oily residue. This was crystallized from acetone-chloroform/hexane (10:1:22); $2.48 \mathrm{~g}$ (62\%); mp $159-160^{\circ} \mathrm{C} ;{ }^{1} \mathrm{H}$ NMR, $\delta: 1.23(\mathrm{~s}, 9 \mathrm{H}$, $\left.{ }^{\mathrm{t}} \mathrm{Bu}\right), 3.28(\mathrm{t}, J=2,3 \mathrm{~Hz}, 1 \mathrm{H}, \mathrm{C} \equiv \mathrm{CH}), 3.96$ (m, 1H, Phg $\left.\mathrm{CH}^{\alpha}\right), 4.36(\mathrm{~d}, J=6.0 \mathrm{~Hz}, 2 \mathrm{H}$, $\left.\mathrm{CH}_{2} \mathrm{C} \equiv \mathrm{C}\right), 6.81\left(\mathrm{t}, J=6.0 \mathrm{~Hz}, 1 \mathrm{H}, \mathrm{NH}-\mathrm{CH}_{2}\right.$ ), $6.88\left(\mathrm{~d}, J=8.7 \mathrm{~Hz}, 2 \mathrm{H}, \mathrm{Ph}: 3^{\prime}-\mathrm{H}\right.$ and $\left.5^{\prime}-\mathrm{H}\right)$, $6.96\left(\mathrm{~d}, J=9.0, \mathrm{SO}_{2}-\mathrm{NH}\right), 7.29(\mathrm{~m}, 3 \mathrm{H}, \mathrm{Ph})$, $7.48(\mathrm{~d}, J=6.3 \mathrm{~Hz}, 2 \mathrm{H}, \mathrm{Ph})$. Anal. Calcd. for $\mathrm{C}_{21} \mathrm{H}_{24} \mathrm{~N}_{2} \mathrm{O}_{4} \mathrm{~S}$ : C, 62.98; H, 6.04; N, 6.99. Found: C, 62.91; H, 6.17; N, 7.08.

tert-Butyl N-[p-(prop-2-ynylamino)benzenesulfonyl]-L-norvalinate (27). A mixture of 21 (3.28 g, $10 \mathrm{mM}), \mathrm{CaCO}_{3}(1.10 \mathrm{~g}, 11 \mathrm{mM})$ and propargyl bromide $(0.86 \mathrm{ml}, 11 \mathrm{mM})$ in DMF $(10 \mathrm{ml})$ was stirred in $29^{\circ} \mathrm{C}$ for $96 \mathrm{~h}$ and then worked up as for $\mathbf{2 2}$. The resulting oil, dissolved in $0.5 \%$ acetone in $\mathrm{CHCl}_{3}(10 \mathrm{ml})$ was purified on a column [gel $(120 \mathrm{~g}), 5 \mathrm{~cm}$ i.d. $\times 14 \mathrm{~cm} \mathrm{~L}$, by elution with a gradient of $0.5-2.5 \%$ acetone in chloroform to give an oily residue. This slowly crystallized from diethyl ether/chloroform/hexane (1:1:2); $2.62 \mathrm{~g}$ (72\%); mp 89.5-92 ${ }^{\circ} \mathrm{C} ;{ }^{1} \mathrm{H} \mathrm{NMR,} \delta: 0.76(\mathrm{t}$, $\left.J=7.2 \mathrm{~Hz}, 3 \mathrm{H},{ }^{\delta} \mathrm{CH}_{3}\right), 1.20\left(\mathrm{~m}, 11 \mathrm{H},{ }^{\mathrm{t}} \mathrm{Bu}\right.$ and

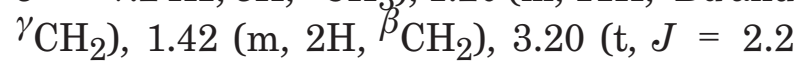
$\mathrm{Hz}, 1 \mathrm{H}, \mathrm{C} \equiv \mathrm{CH}), 3.51\left(\mathrm{~m}, 1 \mathrm{H}, \mathrm{Nva}^{\alpha} \mathrm{CH}\right), 4.34$ $\left(\mathrm{d}, J=6.0 \mathrm{~Hz}, 2 \mathrm{H}, \mathrm{CH}_{2} \mathrm{C} \equiv \mathrm{C}\right), 6.65(\mathrm{~d}$, $J=8.7 \mathrm{~Hz}, 2 \mathrm{H}, \mathrm{Ph}: 3^{\prime}-\mathrm{H}$ and $\left.5^{\prime}-\mathrm{H}\right), 6.82(\mathrm{t}$, $\left.J=6.0 \mathrm{~Hz}, 1 \mathrm{H}, \underline{\mathrm{NH}}-\mathrm{CH}_{2}\right), 6.97(\mathrm{~d}, J=9.0$, $\left.\mathrm{SO}_{2}-\mathrm{NH}\right), 7.68\left(\mathrm{~d}, J=8.7 \mathrm{~Hz}, 2 \mathrm{H}, \mathrm{Ph}: 2^{\prime}-\mathrm{H}\right.$ and $\left.6^{\prime}-\mathrm{H}\right)$. Anal. Calcd. for $\mathrm{C}_{16} \mathrm{H}_{26} \mathrm{~N}_{2} \mathrm{O}_{4} \mathrm{~S}$ : C, 58.99; H, 7.15; N, 7.64. Found: C, 59.17; H, $6.89 ; \mathrm{N}, 7.52$.

Di-tert-Butyl N-[4-[N-(2-amino-3,4-dihydro-4-oxo-6-quinazolinyl)methyl]-N-prop2-ynylamino]benzenesulfonyl]-L-glutamate (28). A mixture of 2-amino-6-bromomethyl-3,4-dihydro-4-oxoquinazoline hydrobromide $(0.40 \mathrm{~g}, 1.1 \mathrm{mM}), \mathrm{CaCO}_{3}(0.11 \mathrm{~g}, 1.1$ $\mathrm{mM})$ and 22 (0.45 g, $1 \mathrm{mM})$ in DMA (2.5 ml) was stirred at $20^{\circ} \mathrm{C}$ in the dark for $96 \mathrm{~h}$. The mixture was diluted with chloroform $(100 \mathrm{ml})$, salts were filtered off, chloroform was evaporated and ethyl acetate $(100 \mathrm{ml})$ added. The organic phase was washed with $\mathrm{H}_{2} \mathrm{O}(3 \times 50 \mathrm{ml})$, $25 \% \mathrm{NH}_{4} \mathrm{OH}$-brine $(9: 1,3 \times 30 \mathrm{ml}), \mathrm{H}_{2} \mathrm{O}(30$ $\mathrm{ml})$ and brine (30 ml), dried over $\mathrm{Na}_{2} \mathrm{SO}_{4}$ and the solvent removed in vacuo. The resulting oil, dissolved in chloroform (10 ml), was purified on a column [gel (40 g), $4 \mathrm{~cm}$ i.d. $\times 6 \mathrm{~cm}$ L], by elution with $10 \%$ acetone in chloroform (100 ml), 2\% methanol in chloroform (25 ml), $4 \%$ methanol in chloroform $(50 \mathrm{ml})$ and $6 \%$ methanol in chloroform $(100 \mathrm{ml})$ to give an oily residue. This was crystallized from ethyl acetate/hexane; $0.32 \mathrm{~g} \mathrm{(52 \% );} \mathrm{mp} 123{ }^{\circ} \mathrm{C} ;{ }^{1} \mathrm{H}$ $\mathrm{NMR}, \delta: 1.17,1.37\left(2 \mathrm{~s}, 18 \mathrm{H}, 2^{\mathrm{t}} \mathrm{Bu}\right), 1.70(\mathrm{~m}$, $\left.2 \mathrm{H},{ }^{\beta} \mathrm{CH}_{2}\right), 2.23\left(\mathrm{~m}, 2 \mathrm{H}, \gamma_{\mathrm{CH}_{2}}\right), 3.21(\mathrm{t}$, $J=2.4 \mathrm{~Hz}, 1 \mathrm{H}, \mathrm{C} \equiv \mathrm{CH}), 3.62\left(\mathrm{~m}, 1 \mathrm{H},{ }^{\alpha} \mathrm{CH}\right)$, $4.30\left(\mathrm{~d}, J=6.0 \mathrm{~Hz}, 2 \mathrm{H}, \mathrm{CH}_{2} \mathrm{C} \equiv \mathrm{C}\right), 4.67(\mathrm{~s}$, $2 \mathrm{H}, \mathrm{ArCH}_{2} \mathrm{~N}<$ ), 6.50 (br s, $2 \mathrm{H}, \mathrm{NH}_{2}$ ), 6.88 (d, $J=8.7,2 \mathrm{H}, \mathrm{Ph}: 3^{\prime}-\mathrm{H}$ and $\left.5^{\prime}-\mathrm{H}\right), 7.16(\mathrm{~d}$, $J=8.0 \mathrm{~Hz}, 1 \mathrm{H}$, quinazoline $8-\mathrm{H}), 7.50(\mathrm{~m}$, $3 \mathrm{H}, \mathrm{Ph}: 2^{\prime}-\mathrm{H}$ and $6{ }^{\prime}-\mathrm{H}$, quinazoline $\left.7-\mathrm{H}\right), 7.81$ (m, $2 \mathrm{H}$, quinazoline 5- $\mathrm{H}$ and $\mathrm{SO}_{2}-\mathrm{NH}$ ). Anal. Calcd. for $\mathrm{C}_{31} \mathrm{H}_{39} \mathrm{~N}_{5} \mathrm{O}_{7} \mathrm{~S}: \mathrm{C}, 59.50 ; \mathrm{H}, 6.28 ; \mathrm{N}$, 11.19. Found: C, 59.22; H, 6.26; N, 10.97 . 
Di-tert-butyl N-[4-[N-(3,4-dihydro-2-methyl-4-oxo-6-quinazolinyl)methyl]-N-prop2-ynylamino]benzenesulfonyl]-L-glutamate (29). A mixture of 22 (0.45 g, $1 \mathrm{mM})$, 6-bromomethyl-3,4-dihydro-2-methyl-4oxoquinazoline $(0.28 \mathrm{~g}, 1.1 \mathrm{mM})$ and $\mathrm{CaCO}_{3}(0.11$ $\mathrm{g}, 1.1 \mathrm{mM})$ in DMA $(2.5 \mathrm{ml})$ was stirred at $20^{\circ} \mathrm{C}$ in the dark for $160 \mathrm{~h}$. Work-up as for $\mathbf{2 8}$ gave 29; $0.323 \mathrm{~g}$, (49\%); mp $112-115^{\circ} \mathrm{C} ;{ }^{1} \mathrm{H}$ $\mathrm{NMR}, \delta: 1.16,1.37\left(2 \mathrm{~s}, 18 \mathrm{H}, 2^{\mathrm{t}} \mathrm{Bu}\right), 1.70(\mathrm{~m}$, $\left.2 \mathrm{H},{ }^{\beta} \mathrm{CH}_{2}\right) 2.22\left(\mathrm{~m}, 2 \mathrm{H},{ }^{\gamma} \mathrm{CH}_{2}\right), 2.32(\mathrm{~s}, 2 \mathrm{H}$, $\mathrm{CH}_{3}-\mathrm{Ar}$ ), $3.22(\mathrm{t}, J=2.3 \mathrm{~Hz}, 1 \mathrm{H}, \mathrm{C} \equiv \mathrm{CH})$, $3.62\left(\mathrm{~m}, 1 \mathrm{H},{ }^{\alpha} \mathrm{CH}\right), 4.35\left(\mathrm{~s}, 2 \mathrm{H}, \mathrm{CH}_{2} \mathrm{C} \equiv \mathrm{C}\right)$, $4.78\left(\mathrm{~s}, 2 \mathrm{H}, \operatorname{ArCH}_{2} \mathrm{~N}<\right), 6.87(\mathrm{~d}, J=8.7 \mathrm{~Hz}$, $2 \mathrm{H}, \mathrm{Ph}: 3^{\prime}-\mathrm{H}$ and $\left.5^{\prime}-\mathrm{H}\right), 7.52(\mathrm{~d}, J=8.1 \mathrm{~Hz}$, $1 \mathrm{H}$, quinazoline 8-H), $7.68(\mathrm{~d}, J=8.1 \mathrm{~Hz}, 1 \mathrm{H}$, quinazoline 7-H), $7.83(\mathrm{~d}, J=8.7 \mathrm{~Hz}, 2 \mathrm{H}, \mathrm{Ph}$ : $2^{\prime}-\mathrm{H}$ and $\left.6^{\prime}-\mathrm{H}\right), 7.98(\mathrm{~s}, 1 \mathrm{H}$, quinazoline $5-\mathrm{H})$, $8.14\left(\mathrm{~d}, J=8.5 \mathrm{~Hz}, 1 \mathrm{H}, \mathrm{SO}_{2} \mathrm{-NH}\right)$. Anal. Calcd. for $\mathrm{C}_{32} \mathrm{H}_{40} \mathrm{~N}_{4} \mathrm{O}_{7} \mathrm{~S}: \mathrm{C}, 61.52 ; \mathrm{H}, 6.45 ; \mathrm{N}$, 8.97. Found: C, 61.24; H, 6.63; N, 8.68.

tert-Butyl N-[4-[N-[(3,4-dihydro-2-methyl-4-oxo-6-quinazolinyl)methyl]-N-prop2-ynylamino]benzenesulfonyl]glycinate (30). A mixture of 23 (0.66 g, $2.2 \mathrm{mM}$ ), 6-bromomethyl-3,4-dihydro-2-methyl-4-oxoquinazoline $(0.51 \mathrm{~g}, 2.0 \mathrm{mM})$ and $\mathrm{CaCO}_{3}(0.20$ $\mathrm{g}, 2.0 \mathrm{mM})$ in DMA $(4 \mathrm{ml})$ and DMF $(10 \mathrm{ml})$ was stirred at $20^{\circ} \mathrm{C}$ in the dark for $168 \mathrm{~h}$. The mixture was diluted with chloroform $(100 \mathrm{ml})$, salts filtered off, chloroform evaporated, and ethyl acetate $(200 \mathrm{ml})$ added. The organic phase was washed with $\mathrm{H}_{2} \mathrm{O}(4 \times 40 \mathrm{ml}), 25 \%$ $\mathrm{NH}_{4} \mathrm{OH} /$ brine $(9: 1,3 \times 40 \mathrm{ml}), 10 \%$ citric acid $(3 \times 30 \mathrm{ml}), \mathrm{H}_{2} \mathrm{O}(30 \mathrm{ml})$ and brine $(30 \mathrm{ml})$, dried over $\mathrm{MgSO}_{4}$ and solvent removed in vacuo. The residue, dissolved in a mixture of DMF (2 ml) and ethyl acetate $(1.5 \mathrm{ml})$, was purified on a column [gel ( $40 \mathrm{~g}), 4 \mathrm{~cm}$ i.d. $\times 8.5$ $\mathrm{cm} \mathrm{L)} \mathrm{using} \mathrm{a} \mathrm{gradient} \mathrm{of} 30-40 \%$ acetone in $\mathrm{CCl}_{4}$ as eluent to give an oily residue. This was crystallized from acetone/hexane; $0.58 \mathrm{~g}$ (58\%); mp 202-203 ${ }^{\circ} \mathrm{C}{ }^{1} \mathrm{H} \mathrm{NMR}, \delta: 0.96$ (s, 9H, ${ }^{\mathrm{t}} \mathrm{Bu}$ ), $2.33\left(\mathrm{~s}, 2 \mathrm{H}, \mathrm{CH}_{3}-\mathrm{Ar}\right), 3.21(\mathrm{t}, J=2.4$ $\mathrm{Hz}, 1 \mathrm{H}, \mathrm{C} \equiv \mathrm{CH}), 3.47(\mathrm{~d}, J=5.0 \mathrm{~Hz}, 2 \mathrm{H}, \mathrm{Gly}$ $\mathrm{CH}_{2}$ ), $4.35\left(\mathrm{~d}, J=6.0,2 \mathrm{H}, \mathrm{CH}_{2} \mathrm{C} \equiv \mathrm{C}\right), 4.79$ (s, $2 \mathrm{H}, \operatorname{ArCH}_{2} \mathrm{~N}<$ ), $5.82(\mathrm{~d}, J=8.7 \mathrm{~Hz}, 2 \mathrm{H}$, Ph: $3^{\prime}-\mathrm{H}$ and $\left.5^{\prime}-\mathrm{H}\right), 7.52(\mathrm{~d}, J=8.4 \mathrm{~Hz}, 1 \mathrm{H}$, quinazoline $8-\mathrm{H}), 7.57(\mathrm{~d}, J=8.9 \mathrm{~Hz}, 1 \mathrm{H}$ quinazoline $7-\mathrm{H}), 7.68\left(\mathrm{~m}, 3 \mathrm{H}, \mathrm{Ph} ; 2^{\prime}-\mathrm{H}\right.$ and $\left.5^{\prime}-\mathrm{H}, \mathrm{SO}_{2}-\mathrm{NH}\right), 7.97(\mathrm{~s}, 1 \mathrm{H}$, quinazoline $5-\mathrm{H})$, 12.2 (br s, lactam NH-). Anal. Calcd. for $\mathrm{C}_{25} \mathrm{H}_{28} \mathrm{~N}_{4} \mathrm{O}_{5} \mathrm{~S}: \mathrm{C}, 60.47 ; \mathrm{H}, 5.68 ; \mathrm{N}, 11.28$. Found: C, 60.63; H, 5.47; N, 11.12.

tert-Butyl N-[4-[N-[(3,4-dihydro-2-methyl-4-oxo-6-quinazolinyl)methyl]-N-prop2-ynylamino]benzenesulfonyl]-L-valinate (31). A mixture of 24 (0.61 g, $1.7 \mathrm{mM})$, 6-bromomethyl-3,4-dihydro-2-methyl-4-oxoqui nazoline $(0.39 \mathrm{~g}, 1.5 \mathrm{mM})$ and $\mathrm{CaCO}_{3}(0.15 \mathrm{~g}$, $1.5 \mathrm{mM})$ in DMF $(2 \mathrm{ml})$ was stirred at $20^{\circ} \mathrm{C}$ in the dark for $100 \mathrm{~h}$. Work-up as for $\mathbf{3 0}$ gave crude product (1.06 g) which, dissolved in chloroform ( $2 \mathrm{ml}$ ), was purified on a column [gel ( $80 \mathrm{~g}), 5 \mathrm{~cm}$ i.d. $\times 9.5 \mathrm{~cm} \mathrm{~L}$ ] using $15 \%$ ethyl acetate in chloroform $(100 \mathrm{ml})$ and a gradient of 1.5-3.0\% methanol in chloroform $(600 \mathrm{ml})$ as eluents to give an oily residue. This was crystallized from ethyl acetate/chloroform/hexane (1:1:2); $0.50 \mathrm{~g}$ (61\%); mp $111-114^{\circ} \mathrm{C} ;{ }^{1} \mathrm{H}$ NMR, $\delta: 0.94(\mathrm{~d}, J=6.8 \mathrm{~Hz}$, $\left.6 \mathrm{H}, \mathrm{CH}\left(\mathrm{CH}_{3}\right)_{2}\right), 1.28\left(\mathrm{~s}, 9 \mathrm{H},{ }^{\mathrm{t}} \mathrm{Bu}\right), 2.32(\mathrm{~s}, 2 \mathrm{H}$, $\mathrm{CH}_{3}-\mathrm{Ar}$ ), (s, 2H, $\mathrm{CH}_{3}-\mathrm{Ar}$ ), $2.33(\mathrm{~m}, 1 \mathrm{H}, \mathrm{Val}$

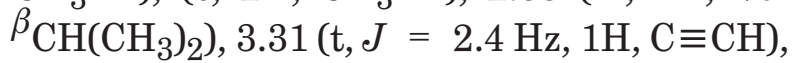
$4.36\left(\mathrm{~d}, J=6.0 \mathrm{~Hz}, 2 \mathrm{H}, \mathrm{CH}_{2} \mathrm{C} \equiv \mathrm{C}\right), 3.65(\mathrm{~m}$, $1 \mathrm{H}, \mathrm{Val}{ }^{\alpha} \mathrm{CH}$ ), 4.20 (s, $2 \mathrm{H}, \mathrm{ArC}_{\underline{H}_{2}} \mathrm{~N}<$ ), 6.87 (d, $J=8.7 \mathrm{~Hz}, 2 \mathrm{H}, \mathrm{Ph}: 3^{\prime}-\mathrm{H}$ and $\left.5^{\prime}-\mathrm{H}\right), 7.76(\mathrm{~d}$, $J=8.7 \mathrm{~Hz}, 2 \mathrm{H}, \mathrm{Ph}: 2^{\prime}-\mathrm{H}$ and $\left.6^{\prime}-\mathrm{H}\right), 7.18(\mathrm{~d}$, $J=8.8 \mathrm{~Hz}, 1 \mathrm{H}$, quinazoline $8-\mathrm{H}), 7.48(\mathrm{dd}$, $J=9.0,1.5 \mathrm{~Hz}, 1 \mathrm{H}$ quinazoline $7-\mathrm{H}), 7.78(\mathrm{~s}$, quinazoline $5-\mathrm{H}), 8.14(\mathrm{~d}, J=9.0,1 \mathrm{H}$, $\left.\mathrm{SO}_{2}-\mathrm{NH}\right)$. Anal. Calcd. for $\mathrm{C}_{28} \mathrm{H}_{34} \mathrm{~N}_{4} \mathrm{O}_{5} \mathrm{~S}: \mathrm{C}$, 62.43; H, 6.36; N, 10.40. Found: C, 62.68; H, $6.09 ; \mathrm{N}, 10.03$.

tert-Butyl N-[4-[N-[(3,4-dihydro-2-methyl-4-oxo-6-quinazolinyl)methyl]-N-prop2-ynylamino]benzenesulfonyl]-L-alaninat $\boldsymbol{e}$ (32). A mixture of 25 (0.69 g, $2.2 \mathrm{mM})$, 6-bromomethyl-3,4-dihydro-2-methyl-4-oxoquinazoline $(0.51 \mathrm{~g}, 2.0 \mathrm{mM})$ and $\mathrm{CaCO}_{3}(0.20 \mathrm{~g}$, $2 \mathrm{mM}$ ) in DMA (4 ml) and DMF (1 ml) was stirred at $20^{\circ} \mathrm{C}$ in the dark for $168 \mathrm{~h}$. Work-up 
as for $\mathbf{3 0}$ gave a crude product $(0.97 \mathrm{~g})$ which, dissolved in a mixture of acetone $(5.5 \mathrm{ml})$ and chloroform ( $3.5 \mathrm{ml})$, was then purified on a column [gel (60 g), $5 \mathrm{~cm}$ i.d. $\times 8 \mathrm{~cm} \mathrm{~L}$ ], using $5 \%$ acetone in chloroform $(50 \mathrm{ml}), 10 \%$ acetone in chloroform (550 ml), and then, 3\% methanol in chloroform $(500 \mathrm{ml})$ as eluents to give an oily residue. This was crystallized from acetone/hexane; $0.44 \mathrm{~g}$ (43\%); $\mathrm{mp}$ 140-142 ${ }^{\circ} \mathrm{C} ; \mathrm{H}^{1} \mathrm{NMR}, \delta: 1.12(\mathrm{~d}, J=7.2 \mathrm{~Hz}$, $\left.3 \mathrm{H}, \mathrm{CHCH}_{3}\right), 1.21\left(\mathrm{~s}, 9 \mathrm{H},{ }^{\mathrm{t}} \mathrm{Bu}\right), 2.32(\mathrm{~s}, 3 \mathrm{H}$, $\left.\mathrm{CH}_{3}-\mathrm{Ar}\right), 3.23(\mathrm{t}, J=2.0 \mathrm{~Hz}, 1 \mathrm{H}, \mathrm{HC} \equiv \mathrm{C})$, $3.62\left(\mathrm{~m}, 1 \mathrm{H},{ }^{\alpha} \mathrm{CH}\right), 4.35(\mathrm{~d}, J=6.0 \mathrm{~Hz}, 2 \mathrm{H}$, $\left.\mathrm{CH}_{2} \mathrm{C} \equiv \mathrm{C}\right), 4.78\left(\mathrm{~s}, 2 \mathrm{H}, \operatorname{ArCH}_{2} \mathrm{~N}<\right), 6.45(\mathrm{~d}$, $J=8.7 \mathrm{~Hz}, 2 \mathrm{H}, \mathrm{Ph}: 3^{\prime}-\mathrm{H}$ and $\left.5^{\prime}-\mathrm{H}\right), 7.54(\mathrm{~d}$, $J=8.7 \mathrm{~Hz}, 2 \mathrm{H}, \mathrm{Ph}: 2^{\prime}-\mathrm{H}$ and $\left.6^{\prime}-\mathrm{H}\right), 7.65(\mathrm{~d}$, $J=8.9 \mathrm{~Hz}, 1 \mathrm{H}$, quinazoline $8-\mathrm{H}), 7.70(\mathrm{dd}$, $J=9.1,1.5 \mathrm{~Hz}, 1 \mathrm{H}$, quinazoline $7-\mathrm{H}), 7.82(\mathrm{~d}$, $\left.J=9.0 \mathrm{~Hz}, 1 \mathrm{H}, \mathrm{SO}_{2}-\mathrm{NH}\right), 7.97(\mathrm{~d}, J=1.5$ $\mathrm{Hz} 1 \mathrm{H}$, quinazoline 5-H), 12.10 (bs, $1 \mathrm{H}$, lactam $\mathrm{NH}$ ). Anal. Calcd. for $\mathrm{C}_{26} \mathrm{H}_{30} \mathrm{~N}_{4} \mathrm{O}_{5} \mathrm{~S}$ : C, 61.16; H, 5.92; N, 10.97. Found: C, 61.38; H, 6.09; N, 10.82 .

tert-Butyl $\mathrm{N}-[4-[\mathrm{N}-[(3,4-d i h y d r o-2-m e-$ thyl-4-oxo-6-quinazolinyl)methyl]-N-prop2-ynylamino]benzenesulfonyl]-L-phenylglycinate (33). A mixture of 26 (0.88 g, 2.2 mmol), 6-bromomethyl-3,4-dihydro-2-methyl4-oxoquinazoline $(0.51 \mathrm{~g}, 2.0 \mathrm{mM})$ and $\mathrm{CaCO}_{3}$ $(0.20 \mathrm{~g}, 2 \mathrm{mM})$ in DMF (3 ml) was stirred at $20^{\circ} \mathrm{C}$ in the dark for $168 \mathrm{~h}$. Work-up as for 30 gave a crude product (1.36 g) which, dissolved in a mixture of chloroform, ethyl acetate and methanol $(3.5 \mathrm{ml}, 1.0 \mathrm{ml}$ and $0.2 \mathrm{ml}$, respectively), was purified on a column [gel ( $80 \mathrm{~g}), 5$ $\mathrm{cm}$, i.d. $\times 10 \mathrm{~cm} \mathrm{L]} \mathrm{using} \mathrm{as} \mathrm{eluents} 10 \%$ ethyl acetate in chloroform (100 $\mathrm{ml}), 15 \%$ ethyl acetate in chloroform (100 ml), $20 \%$ ethyl acetate in chloroform $(100 \mathrm{ml})$ and then, a gradient $1.0-2.5 \%$ methanol in chloroform, to give an oily residue. This was crystallized from acetone/hexane; $0.75 \mathrm{~g}(66 \%) ; \mathrm{mp} 176-178^{\circ} \mathrm{C} ; \mathrm{H}^{1}$ NMR, $\delta: 1.22\left(\mathrm{~s}, 9 \mathrm{H},{ }^{\mathrm{t}} \mathrm{Bu}\right), 2.32(\mathrm{~s}, 3 \mathrm{H}$, $\mathrm{CH}_{3}$-Ar), $3.20(\mathrm{t}, J=2.3 \mathrm{~Hz}, 1 \mathrm{H}, \mathrm{C} \equiv \mathrm{CH}$ ), $3.96\left(\mathrm{~m}, 1 \mathrm{H},{ }^{\alpha} \mathrm{CH}\right), 4.32(\mathrm{~d}, J=6.0 \mathrm{~Hz}, 2 \mathrm{H}$,

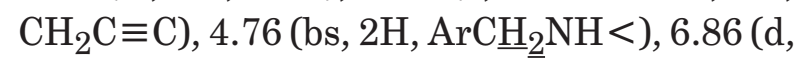

$J=8.7 \mathrm{~Hz}, 2 \mathrm{H}, \mathrm{Ph}: 3^{\prime}-\mathrm{H}$, and $\left.5^{\prime}-\mathrm{H}\right), 7.93(\mathrm{~d}$, $J=8.7 \mathrm{~Hz}, 2 \mathrm{H}, \mathrm{Ph}: 2^{\prime}-\mathrm{H}$, and $\left.6^{\prime}-\mathrm{H}\right)$, 7.25-7.36 (m, 4H, $\mathrm{Ph}$ and quinazoline $8-\mathrm{H})$, 7.53-7.70 (m, 3H, Ph, quinazoline 7-H), 8.15 (d, $J=1.5 \mathrm{~Hz}, 1 \mathrm{H}$, quinazoline 5-H). Anal. Calcd. for $\mathrm{C}_{31} \mathrm{H}_{32} \mathrm{~N}_{4} \mathrm{O}_{5} \mathrm{~S}$ : C, 65.02; H, 5.63; N, 9.78. Found: C, 65.11; H, 5.60; N, 9.81.

tert-Butyl N-[4-[N-[(3,4-dihydro-2-methyl-4-oxo-6-quinazolinyl)methyl]-N-prop2-ynylamino]benzenesulfonyl]-L-norvalinate (34). A mixture of 27 (0.75 g, $2.2 \mathrm{mM})$, 6-bromomethyl-3,4-dihydro-2-methyl-4-oxoquinazoline $(0.51 \mathrm{~g}, 2.0 \mathrm{mM})$ and $\mathrm{CaCO}_{3}(0.20 \mathrm{~g}$, $2 \mathrm{mM}$ ) in DMA (4 ml) and DMF (1 ml) was stirred at $20^{\circ} \mathrm{C}$ in the dark for $168 \mathrm{~h}$. Work up as for 30 furnished a crude product (1.11 g) which, dissolved in $2 \%$ methanol in chloroform ( $3 \mathrm{ml}$ ) was purified on a column [gel (54 g), $4 \mathrm{~cm}$, i.d. $\times 10 \mathrm{~cm} \mathrm{~L}$, using a gradient of $2.6-3.5 \%$ methanol in chloroform $(500 \mathrm{ml})$ as eluent to give an oily residue. This was crystallized from acetone/hexane; $0.63 \mathrm{~g}$ (59\%); mp $176-178^{\circ} \mathrm{C} ;{ }^{1} \mathrm{H}$ NMR, $\delta: 0.75$ (t, $3 \mathrm{H}, \mathrm{CH}_{2} \mathrm{CH}_{3}$ ), $1.22\left(\mathrm{~m}, 11 \mathrm{H},{ }^{\mathrm{t}} \mathrm{Bu}\right.$ and $\left.\gamma_{\mathrm{CH}_{2}}\right), 1.43(\mathrm{~m}, 2 \mathrm{H}$, $\beta_{\mathrm{CH}_{2}}$ ), 2.32 (s, 2H, $\mathrm{CH}_{3}-\mathrm{Ar}$ ), 3.21 (t, $J=2.2$ $\mathrm{Hz}, 1 \mathrm{H}, \mathrm{C} \equiv \mathrm{CH}), 3.51\left(\mathrm{~m}, 1 \mathrm{H},{ }^{\alpha} \mathrm{CH}\right), 4.34(\mathrm{~d}$, $\left.J=6.0 \mathrm{~Hz}, 2 \mathrm{H}, \mathrm{CH}_{2} \mathrm{C} \equiv \mathrm{C}\right), 6.65(\mathrm{~d}, J=8.7$ $\mathrm{Hz}, 2 \mathrm{H}, \mathrm{Ph}: 3^{\prime}-\mathrm{H}$ and $\left.5^{\prime}-\mathrm{H}\right), 7.12(\mathrm{~d}, J=8.0$ $\mathrm{Hz}, 1 \mathrm{H}$, quinazoline $8-\mathrm{H}), 7.50(\mathrm{~m}, 3 \mathrm{H}, \mathrm{Ph}$ : $2^{\prime}-\mathrm{H}$, and $5^{\prime}-\mathrm{H}$ and quinazoline $\left.7-\mathrm{H}\right), 7.83(\mathrm{~m}$, $2 \mathrm{H}$, quinazoline 5 - $\mathrm{H}$ and $\left.\mathrm{SO}_{2}-\mathrm{NH}\right)$. Anal. Calcd. for $\mathrm{C}_{28} \mathrm{H}_{34} \mathrm{~N}_{4} \mathrm{O}_{5} \mathrm{~S}$ : C, 62.43; H, 6.36; N, 10.40. Found: C, 62.67; H, 6.12; N, 10.18 .

N-[p-[N-(3,4-dihydro-2-amino-4-oxo-6-quinazolinyl)methyl]-N-prop-2-ynylaminolbenzenesulfonyl]-L-glutamic acid (3), N-[p-[N-(3,4-dihydro-2-methyl-4-oxo-6-qui nazolinyl)methyl]-N-prop-2-ynylamino]be nzenesulfonyl]-L-glutamic acid (4), -glycine (5), -L-valine (6), -L-alanine (7), -L-phenylglycine (8) and -L-norvaline (9). General procedure. A solution of each of 28-34 in trifluoroacetic acid $(10 \mathrm{ml} / \mathrm{mM})$ was stored for $1 \mathrm{~h}$ at room temp. TLC (system B) showed the absence of starting material. The acid was evaporated and diethyl ether $(100 \mathrm{ml} / \mathrm{mM})$ 
Table 2. Sulfamide antifolates (3-9)

\begin{tabular}{|c|c|c|c|c|c|c|c|}
\hline \multirow{2}{*}{$\begin{array}{l}\text { Compd. } \\
\text { No. }\end{array}$} & \multirow{2}{*}{$\begin{array}{l}\text { Yield } \\
\%^{\mathrm{a}}\end{array}$} & \multirow{2}{*}{$\begin{array}{l}\mathrm{mp} \\
{ }^{\circ} \mathrm{C}\end{array}$} & \multirow{2}{*}[\mathrm{M}+1]{$^{+}$} & \multirow{2}{*}{ Formula } & \multicolumn{3}{|c|}{ Anal. Calcd. (Found) } \\
\hline & & & & & C & $\mathrm{H}$ & $\mathrm{N}$ \\
\hline 3 & 92 & $\begin{array}{l}169- \\
172\end{array}$ & 514 & $\begin{array}{c}\mathrm{C}_{23} \mathrm{H}_{23} \mathrm{~N}_{5} \mathrm{O}_{7} \mathrm{~S} \cdot 0.5 \mathrm{CF}_{3} \mathrm{COOH} \\
\cdot 0.1\left(\mathrm{C}_{2} \mathrm{H}_{5}\right)_{2} \mathrm{O} \cdot 0.5 \mathrm{H}_{2} \mathrm{O}\end{array}$ & $\begin{array}{r}49.97 \\
(49.63\end{array}$ & $\begin{array}{l}4.34 \\
4.39\end{array}$ & $\begin{array}{l}11.93 \\
11.91)\end{array}$ \\
\hline 4 & 91 & $\begin{array}{l}140- \\
142\end{array}$ & 513 & $\mathrm{C}_{24} \mathrm{H}_{24} \mathrm{~N}_{4} \mathrm{O}_{7} \mathrm{~S} \cdot 0.6 \mathrm{CF}_{3} \mathrm{COOH}$ & $\begin{array}{r}52.09 \\
(52.13\end{array}$ & $\begin{array}{l}4.27 \\
4.18\end{array}$ & $\begin{array}{l}9.64 \\
9.55)\end{array}$ \\
\hline 5 & 98 & $\begin{array}{l}231- \\
233\end{array}$ & 441 & $\begin{array}{c}\mathrm{C}_{21} \mathrm{H}_{20} \mathrm{~N}_{4} \mathrm{O}_{5} \mathrm{~S} \cdot 0.4 \mathrm{CF}_{3} \mathrm{COOH} \\
\cdot 0.5 \mathrm{H}_{2} \mathrm{O}\end{array}$ & $\begin{array}{r}52.88 \\
(52.72\end{array}$ & $\begin{array}{l}4.36 \\
4.35\end{array}$ & $\begin{array}{l}11.32 \\
11.28)\end{array}$ \\
\hline 6 & 98 & $\begin{array}{l}212- \\
215\end{array}$ & 483 & $\begin{array}{c}\mathrm{C}_{24} \mathrm{H}_{26} \mathrm{~N}_{4} \mathrm{O}_{5} \mathrm{~S} \cdot 0.5 \mathrm{CF}_{3} \mathrm{COOH} \\
\cdot 0.4 \mathrm{H}_{2} \mathrm{O}\end{array}$ & $\begin{array}{r}54.91 \\
(54.85\end{array}$ & $\begin{array}{l}5.03 \\
5.07\end{array}$ & $\begin{array}{l}10.25 \\
10.17)\end{array}$ \\
\hline 7 & 98 & 246 & 455 & $\begin{array}{c}\mathrm{C}_{22} \mathrm{H}_{22} \mathrm{~N}_{4} \mathrm{O}_{5} \mathrm{~S} \cdot 0.3 \mathrm{CF}_{3} \mathrm{COOH} \\
\cdot 0.5 \mathrm{H}_{2} \mathrm{O}\end{array}$ & $\begin{array}{r}54.53 \\
(54.42\end{array}$ & $\begin{array}{l}4.72 \\
4.81\end{array}$ & $\begin{array}{l}11.26 \\
11.21)\end{array}$ \\
\hline 8 & 97 & $\begin{array}{l}215- \\
217\end{array}$ & 517 & $\begin{array}{c}\mathrm{C}_{27} \mathrm{H}_{24} \mathrm{~N}_{4} \mathrm{O}_{5} \mathrm{~S} \cdot 0.7 \mathrm{CF}_{3} \mathrm{COOH} \\
\cdot 0.5 \mathrm{H}_{2} \mathrm{O}\end{array}$ & $\begin{array}{r}57.28 \\
(57.15\end{array}$ & $\begin{array}{l}4.35 \\
4.38\end{array}$ & $\begin{array}{l}9.41 \\
9.45)\end{array}$ \\
\hline 9 & 98 & $\begin{array}{l}226- \\
229\end{array}$ & 483 & $\begin{array}{c}\mathrm{C}_{24} \mathrm{H}_{26} \mathrm{~N}_{4} \mathrm{O}_{5} \mathrm{~S} \cdot 0.6 \mathrm{CF}_{3} \mathrm{COOH} \\
\cdot 0.2 \mathrm{H}_{2} \mathrm{O}\end{array}$ & $\begin{array}{r}61.14 \\
(61.12\end{array}$ & $\begin{array}{l}4.53 \\
4.52\end{array}$ & $\begin{array}{l}10.11 \\
10.02)\end{array}$ \\
\hline
\end{tabular}

a. Preparation in $0.5 \mathrm{mM}$ scale

added. The white solid that precipitated was purified by six cycles of centrifugation-decantation-resuspension in diethyl ether. The product was dried in vacuo over $\mathrm{KOH}$ at $65^{\circ} \mathrm{C}$ overnight. Yields, analytical data and $[\mathrm{M}+1]^{+}$ ions of 3-9 are given in Table 2, and ${ }^{1} \mathrm{H}$ NMR data in Table 3.

\section{Biology}

Cells. Mouse leukemia L5178Y cells were grown as reported earlier (Dzik et al., 1996).

In vitro cell growth inhibition. The influence of each analogue on viability of exponentially growing cells and $\left[{ }^{14} \mathrm{C}\right]$ leucine incorpo-

Table $3 .{ }^{1} \mathrm{H}$ NMR spectra of sulfamide antifolates (3-9)



a,b $1.75\left(\mathrm{~m}, 2 \mathrm{H}, \mathrm{Glu}^{\beta} \mathrm{CH}_{2}\right), 2.20\left(\mathrm{t}, J=6.8,2 \mathrm{H}, \mathrm{Glu}^{\gamma} \mathrm{CH}_{2}\right) ;{ }^{\mathrm{c}} 3.47\left(\mathrm{~d}, J=6 \mathrm{~Hz}, 2 \mathrm{H}, \mathrm{Gly} \mathrm{CH}_{2}\right) ;{ }^{\mathrm{d}} 1.07\left[\mathrm{~d}, J=6.4 \mathrm{~Hz}, 6 \mathrm{H}, \mathrm{CH}\left(\mathrm{CH}_{3}\right)_{2}\right]$, $2.34\left[\left(\mathrm{~m}, 1 \mathrm{H}, \mathrm{Val}^{\beta} \mathrm{CH}\left(\mathrm{CH}_{3}\right)_{2}\right] ;{ }^{\mathrm{e}} 1.12\left(\mathrm{~d}, J=7.3 \mathrm{~Hz}, 3 \mathrm{H}, \mathrm{Ala} \mathrm{CH}_{3}\right) ;{ }^{\mathrm{f}} 7.25-7.36\left(\mathrm{~m}, 4 \mathrm{H}\right.\right.$, quinazoline $\mathrm{H}^{8}$ and Phg Ph $), 7.53-7.70(\mathrm{~m}, 3 \mathrm{H}$ quinazoline $\mathrm{H}^{7}$ and Phg Ph); ${ }^{\mathrm{g}} 0.76\left(\mathrm{t}, J=7.3,3 \mathrm{H}, \mathrm{Nva}^{\delta} \mathrm{CH}_{3}\right), 1.21\left(\mathrm{~m}, 2 \mathrm{H}, \mathrm{Nva}{ }^{\gamma} \mathrm{CH}_{2}\right), 1.43\left(\mathrm{q}, J=7.3,2 \mathrm{H}, \mathrm{Nva}^{\beta} \mathrm{CH}_{2}\right)$. 
ration was followed, and $\mathrm{IC}_{50}$ values determined as previously described (Dzik et al., 1996).

Thymidylate synthase. Highly purified preparations of thymidylate synthase from mouse Ehrlich carcinoma cells (Jastreboff et al., 1983), regenerating rat liver and the tapeworm Hymenolepis diminuta (Rode et al., 1990) have been described in detail elsewhere.

Enzyme assay. Thymidylate synthase activity was assayed by monitoring release of tritium from $\left[5-{ }^{3} \mathrm{H}\right] \mathrm{dUMP}$ as previously described (Rode et al., 1984), all measurements being done in triplicate. $N^{10}$-propargyl-5,8-dideazafolate and its analogues were added to the reaction mixture as neutral aqueous solutions.

Kinetic studies. To identify the type of inhibition involved, the effects of each analogue on the dependence of reaction rate on $N^{5,10}$-methylenetetrahydrofolate concentration, in the form of Lineweaver-Burk plots, were analyzed as previously reported (Rode et al., 1984).

Statistically evaluated results. These are presented as means \pm S.E.M. or means $\pm \%$ difference between the mean and each of the two results, followed by the number of experiments $(\mathrm{N})$ in parentheses.

\section{RESULTS}

\section{Chemistry}

The synthetic route to compounds $\mathbf{3 - 9}$ (Fig. 2) started with $p$-nitrobenzenesulfonylchloride coupling with an appropriate amino acid tert-butyl ester to give the nitro derivatives (10-15) which, after catalytic hydrogenation, furnished $N$-( $p$-aminobenzenesulfonyl)amino acid tert-butyl esters (16-21). Their N-alkylation with propargyl bromide yielded secondary amines (22-27). The second N-alkylation with 2-amino-6-bromomethyl-3,4-dihydro-4-oxoquinazoline or 6-bromomethyl-3,4-dihydro-2-methyl-4-oxoquinazoline led to the antifolate esters (28-34). Final removal of the tert-butyl group with trifluoroacetic acid gave the appropriate antifolates (3-9). Purity of all compounds 3-34 was established by elemental analysis, and the structures of 22-34 and 3-9 were confirmed by ${ }^{1} \mathrm{H}$ NMR spectroscopy. The final products 3-9 were additionally characterised by FABmass spectrometry.

\section{Biological evaluation}

While replacement of $\mathrm{CONH}$ by $\mathrm{SO}_{2} \mathrm{NH}$ in the parent pddPteGlu (1) resulted in 3-10fold weaker inhibition of the enzyme (Table 4; compound 3), the same modification of $\mathbf{2}$ led to a 5 -fold loss in thymidylate synthase inhibition potency and an 8-9-fold decrease in cell growth inhibition potency (Tables 4-5; compound 4). Substitution of the glutamyl residue in 4 with norvaline resulted in 2-5-fold stronger thymidylate synthase inhibition, but almost 4-5-fold weaker growth inhibition (Tables 4-5; compound 9). Similar substitutions with glycine, alanine, valine and phenylglycine were either without a distinct effect (Table 4; compounds 7-8, and $\mathbf{5}$ with regenerating rat liver enzyme) or lowered enzyme inhibitory potency (Table 4; compounds $\mathbf{6}$, and $\mathbf{7}$ with the tumour and parasite enzyme). The analogues substituted with glycine and alanine caused 4-7-fold weaker cell growth inhibition than compound 4 (Table 5, compounds $\mathbf{5}$ and $\mathbf{7}$ ).

\section{DISCUSSION}

pddPteGlu was the first thymidylate synthase-targeted antifolate tested as an antitumour drug in clinical trials (Rosowsky, 1992). Although it showed significant activity against a number of human tumours, undesirable side effects, such as liver toxicity and kidney toxicity, resulting from poor solubility, prevented its use (Harrap et al., 1995). Replacement of the amino group at C(2) by a hy- 


<smiles>[R]C(NC(=O)c1ccc(NCC#C)cc1)C(=O)OC</smiles>

22-27<smiles>CC#CCCCC</smiles><smiles>[R]C(NC(=O)c1ccc(N)cc1)C(=O)OC</smiles>

$16-21$

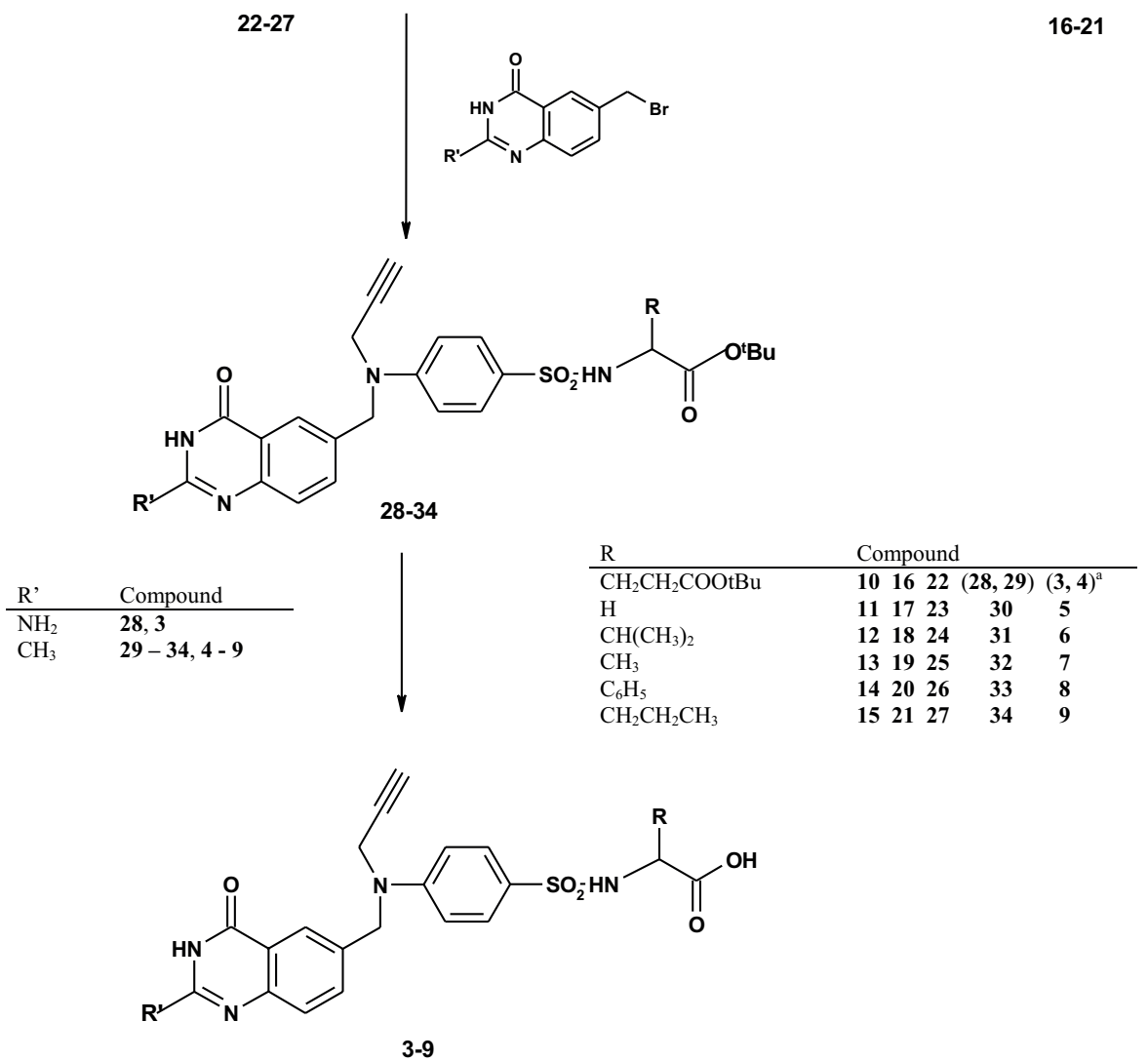

Figure 2. Synthesis of the new analogues 3-9.

drogen or a methyl group led to several-fold weaker binding to thymidylate synthase, but with substantially increased solubility, with no distinct loss of antitumour activity (Jones et al., 1989). The 2-methyl substitution resulted in particularly strong cell growth inhibition (Jackman et al., 1991), presumably due to more efficient conversion of the 2-methyl derivative to non-effluxing long-chain polyglutamates, known to be stronger thymidylate synthase inhibitors. In accord with the forego- ing, results presented here show also a 4-5-fold weaker inhibition of rat thymidylate synthase and unchanged cell growth inhibition resulting from the 2-methyl substitution in a pddPteGlu derivative (Tables 4-5, cf. pddPteSO $\mathrm{S}_{2} \mathrm{Glu}$ and $\mathrm{CH}_{3}$ pddPteSO $\mathrm{S}_{2} \mathrm{Glu}$ ). It should be noted that the L5178Y cells used in our experiments were 2-20-fold less sensitive to growth inhibition than L1210 cells by several known antifolates (Kusakiewicz-Dawid et al., 2002). 
Replacement of $\mathrm{CONH}$ by $\mathrm{SO}_{2} \mathrm{NH}$ in $\mathrm{CH}_{3}$ pddPteGlu weakened inhibition of both the enzyme and cell growth (Tables 4-5). Several thymidylate synthase inhibitors have been synthesized, containing $-\mathrm{SO}_{2} \mathrm{NH}-$ or $\mathrm{SO}_{2} \mathrm{~N}=$ sulfonamide group (Elslager et al., 1984; Pendergast et al., 1993; Varney et al., 1992; Jones et al., 1996). One of them, AG 331, entered clinical studies (Bavetsias \& Jackman, 1998). Some members of a series of 2,4-diamino-6-quinazolinesulfonamides showed strong antimalarial activity (Elslager et al., 1984) but were not tested against potential target enzymes. Recently, introduction of the sulfonamido $\left(\mathrm{SO}_{2} \mathrm{NH}\right)$ link into benzoquinazoline derivatives inhibiting thymidylate synthase resulted in compounds with $K_{\mathrm{i}}$ values in the $\mathrm{nM}$ range (Pendergast et al., 1993). Amongst nonpolyglutamable analogu- es of 2-deamino-2-methyl-10-propargyl-5,8-dideazafolic acid 2 (Fig. 1), that containing a phenyl ring with a 3-fluoromethyl group at the position $2 v s . \mathrm{N}^{10}$, bound with the glycyl residue via a sulfonamide bond, was as potent an enzyme inhibitor as the parent compound, but a weak cell growth inhibitor (Jones et al., 1996).

Substitution of the glutamyl residue in $\mathrm{CH}_{3}$ pddPteSO $\mathrm{S}_{2} \mathrm{Glu}$ with different amino-acid residue (Ala, Gly,Val, PhGly or NVal) appears to offer new derivatives with moderate specificity, reflected by several-fold differences in inhibitory potency against thymidylate synthases of different origin (Table 4). Interestingly, while previously described similar substitutions of the glutamyl residue in pddPteGlu with Ala and Gly resulted in distinctly lower, relative to the parent com-

Table 4. Inhibition of Ehrlich carcinoma (Ehrlich c.), Hymenolepis diminuta (H.d.) and regenerating rat liver (RRL) thymidylate synthases by10-propargyl-5,8-dideazafolic acid (pddPteGlu; 1) and its 2-methyl-2-desamino analogue (ICI 198583; 2), sulphonamide analogues of 1 and 2 (PddPteSO Glu and $\mathrm{CH}_{3}$ pddPteSO $\mathrm{O}_{2} \mathrm{Glu}$, respectively), and sulphonamide analogues of 2 with glutamyl residue substituted by glycyl (in $\mathrm{CH}_{3}$ pddPteSO ${ }_{2}$ Gly), valyl (in $\mathrm{CH}_{3}$ pddPteSO 2 Val), alanyl (in $\mathrm{CH}_{3}$ pddPteSO 2 Ala), phenylglycyl (in $\mathrm{CH}_{3}$ pddPteSO ${ }_{2} \mathrm{PhGly}$ ) or norvalyl (in $\mathrm{CH}_{3}$ pddPteSO ${ }_{2} \mathrm{NVal}$ ) residue; for structures see Fig. 1.

\begin{tabular}{|c|c|c|c|c|c|c|c|c|c|}
\hline \multicolumn{4}{|l|}{ Compound } & \multicolumn{2}{|l|}{ Ehrlich c. enzyme } & \multicolumn{2}{|l|}{ H.d. enzyme } & \multicolumn{2}{|l|}{ RRL enzyme } \\
\hline No. & $\mathrm{R}$ & $\mathrm{X}$ & $\mathrm{R}^{\prime}$ & $K_{\mathrm{i}}(\mu \mathrm{M})$ & $K_{\mathrm{i}} / K_{\mathrm{m}}$ & $K_{\mathrm{i}}(\mu \mathrm{M})$ & $K_{\mathrm{i}} / K_{\mathrm{m}}$ & $K_{\mathrm{i}}(\mu \mathrm{M})$ & $K_{\mathrm{i}} / K_{\mathrm{m}}$ \\
\hline pddPteGlu (1) & $\mathrm{NH}_{2}$ & $\mathrm{CO}$ & $\mathrm{Glu}^{\mathrm{a}}$ & $0.008 \pm 0.002(3)$ & 0.00024 & $0.017^{\mathrm{b}}$ & 0.00057 & $0.010^{\mathrm{b}}$ & 0.00042 \\
\hline ICI 198583 (2) & $\mathrm{CH}_{3}$ & $\mathrm{CO}$ & Glu & $0.010^{\mathrm{c}}$ & & $\mathrm{ND}^{\mathrm{d}}$ & & $0.039^{\mathrm{e}}$ & 0.0014 \\
\hline pddPteSO $_{2}$ Glu (3) & $\mathrm{NH}_{2}$ & $\mathrm{SO}_{2}$ & Glu & $0.082 \pm 0.008(3)$ & 0.0024 & $0.049 \pm 0.005(3)$ & 0.0016 & $0.051 \pm 0.000(3$ & 0.0021 \\
\hline $\mathrm{CH}_{3} \mathrm{pddPteSO}_{2} \mathrm{Glu}(\mathbf{4})$ & $\mathrm{CH}_{3}$ & $\mathrm{SO}_{2}$ & Glu & $0.192 \pm 0.010(3)$ & 0.0057 & $0.27 \pm 0.01(3)$ & 0.0090 & $0.21 \pm 0.02(3)$ & 0.0087 \\
\hline $\mathrm{CH}_{3}$ pddPteSO ${ }_{2}$ Gly (5) & $\mathrm{CH}_{3}$ & $\mathrm{SO}_{2}$ & Gly & $0.303 \pm 0.061(3)$ & 0.0090 & $0.66^{\mathrm{b}}$ & 0.022 & $0.16^{\mathrm{b}}$ & 0.0067 \\
\hline $\mathrm{CH}_{3}$ pddPteSO $_{2} \mathrm{Val}(\mathbf{6})$ & $\mathrm{CH}_{3}$ & $\mathrm{SO}_{2}$ & Val & $0.386 \pm 0.074(3)$ & 0.012 & $0.93^{\mathrm{b}}$ & 0.031 & $0.29^{\mathrm{b}}$ & 0.012 \\
\hline $\mathrm{CH}_{3}$ pddPteSO$_{2} \mathrm{Ala}(7)$ & $\mathrm{CH}_{3}$ & $\mathrm{SO}_{2}$ & Ala & $0.184 \pm 0.022(3)$ & 0.0055 & $0.17^{\mathrm{b}}$ & 0.0057 & $0.14^{b}$ & 0.0058 \\
\hline $\mathrm{CH}_{3}$ pddPteSO ${ }_{2}$ PhGly (8) & $\mathrm{CH}_{3}$ & $\mathrm{SO}_{2}$ & PhGly & $0.150 \pm 0.020(3)$ & 0.0045 & $0.55^{\mathrm{b}}$ & 0.018 & $0.22^{b}$ & 0.0092 \\
\hline $\mathrm{CH}_{3} \mathrm{pddPteSO}_{2} \mathrm{NVal}(\mathbf{9})$ & $\mathrm{CH}_{3}$ & $\mathrm{SO}_{2}$ & NVal & $0.048 \pm 0.001(3)$ & 0.0014 & $0.14 \pm 0.01(3)$ & 0.0047 & $0.085 \pm 0.013(3$ & 0.0035 \\
\hline
\end{tabular}

a Amino-acid residue abbreviations: glutamic acid (Glu), glycine (Gly), valine (Val), alanine (Ala), phenylglycine (PhGly), norvaline (NVal); ${ }^{b}$ Mean result of two experiments differing by not more than $20 \%$. ${ }^{\text {c }}$ Thymidylate synthase from murine leukaemia L1210 cells; Hughes et al. 1990; ${ }^{\mathrm{d}}$ Not determined. ${ }^{\mathrm{e}}$ Recombinant rat hepatoma thymidylate synthase; KusakiewiczDawid et al. 2002. 
Table 5. Inhibition of murine leukaemia L518Y cell growth by 10-propargyl-5,8-dideazafolic acid (pddPteGlu; 1) and its 2-methyl-2-desamino analogue (ICI 198583; 2), sulphonamide analogue of 2 $\left(\mathrm{CH}_{3}\right.$ pddPteSO ${ }_{2} \mathrm{Glu}$, respectively), and sulphonamide analogues of 2 with glutamyl residue substituted by glycyl (in $\mathrm{CH}_{3}$ pddPteSO ${ }_{2} \mathrm{Gly}$ ), alanyl (in $\mathrm{CH}_{3}$ pddPteSO $\mathrm{Sla}_{2} \mathrm{Ala}$ ), or norvalyl (in $\mathrm{CH}_{3} \mathrm{pddPteSO}_{2} \mathrm{NVal}_{\text {) res- }}$ idue; for structures see Fig. 1.

\begin{tabular}{|c|c|c|c|c|c|}
\hline \multicolumn{3}{|c|}{ Compound } & \multicolumn{3}{|c|}{ Cell growth inhibition $\left[\mathrm{IC}_{50}(\mu \mathrm{M})\right]$} \\
\hline Abbreviation (No.) & $\mathrm{R}$ & $\mathrm{X}$ & $\mathrm{R}^{\prime}$ & Cell count & {$\left[{ }^{14} \mathrm{C}\right]$ Leu incorporation } \\
\hline pddPteGlu (1) & $\mathrm{NH}_{2}$ & $\mathrm{CO}$ & Glu & $9.05 \pm 1.24(3)$ & $8.3 \pm 1.21(3)$ \\
\hline $\mathrm{CH}_{3}$ pddPteGlu; ICI 198583 (2) & $\mathrm{CH}_{3}$ & $\mathrm{CO}$ & Glu & $6.9 \pm 7 \%(2)$ & $6.61 \pm 15 \%(2)$ \\
\hline $\mathrm{CH}_{3}$ pddPteSO $_{2}$ Glu (4) & $\mathrm{CH}_{3}$ & $\mathrm{SO}_{2}$ & Glu & $59.5 \pm 2.5 \%(2)$ & $54.6 \pm 28 \%(2)$ \\
\hline $\mathrm{CH}_{3}$ pddPteSO ${ }_{2}$ Gly (5) & $\mathrm{CH}_{3}$ & $\mathrm{SO}_{2}$ & Gly & $210 \pm 12 \%(2)$ & $270 \pm 25 \%(2)$ \\
\hline $\mathrm{CH}_{3}$ pddPteSO 2 Ala (7) & $\mathrm{CH}_{3}$ & $\mathrm{SO}_{2}$ & Ala & $451 \pm 3 \%(2)$ & $399 \pm 14 \%(2)$ \\
\hline $\mathrm{CH}_{3} \mathrm{pddPteSO}_{2} \mathrm{NVal}(\mathbf{9})$ & $\mathrm{CH}_{3}$ & $\mathrm{SO}_{2}$ & NVal & $290 \pm 11 \%(2)$ & $204 \pm 4 \%(2)$ \\
\hline
\end{tabular}

pound, affinities for mammalian thymidylate synthase (Jones et al., 1986), the same substitutions in the $\mathrm{CH}_{3}$ pddPteSO${ }_{2} \mathrm{Glu}$ molecule seemed to be without effect (Table 4). All the new analogues with the glutamyl residue replaced by different amino-acid residues, compared with the parent $\mathrm{CH}_{3}$ pddPteSO $\mathrm{S}_{2} \mathrm{Glu}$, were several-fold weaker inhibitors of cell growth (cf. Jones et al., 1986; Marsham et al., 1995). This is not surprising, since these compounds cannot be substrates for folylpolyglutamate synthetase.

Of particular interest are the properties of the new analogue containing norvaline in place of the glutamate residue $\left(\mathrm{CH}_{3}\right.$ pddPteSO $\left.{ }_{2} \mathrm{NVal}\right)$, being a several-fold stronger inhibitor of the three thymidylate synthases than $\mathrm{CH}_{3}$ pd$\mathrm{dPteSO}_{2} \mathrm{Glu}$, and either only several-fold weaker (with the mammalian enzyme) or as potent (with tapeworm enzyme) inhibitor as the parent $\mathrm{CH}_{3}$ pddPteGlu (Table 4).

\section{R E F E R E N C E S}

Bavetsias V, Jackman AL. (1998) Nonpolyglutamatable antifolates as inhibitors of thymidylate synthase (TS) and potential antitumour agents. Curr Med Chem.; 5: $265-88$.
Calvert AH, Jones TR, Jackman AL, Brown SJ, Harrap KR. (1980) An approach to the design of antimetabolites active against cells resistant to conventional agents illustrated by quinazoline antifolates with $\mathrm{N}^{10}$-substitutions. In Human cancer, its characterisation and treatment. Davis W, Harrap KR, Stathopoulos G. eds, pp 272-83. Excerpta Medica, Amsterdam.

Carreras CW, Santi DV. (1995). The catalytic mechanism and structure of thymidylate synthase. Annu Rev Biochem.; 64: 721-62.

Dzik JM, Bretner M, Kulikowski T, Gołos B, Jarmuła A, Poznański J, Rode W, Shugar D. (1996) Synthesis and interactions with thymidylate synthase of 2,4-dithio-analogues of dUMP and 5-fluoro-dUMP. Biochim Biophys Acta.; 1293: 1-8.

Elslager EF, Colbry NL, Davoll J, Hutt MP, Johnson JL, Werbel LM. (1984) Folate antagonists. 22. Antimalarial and antibacterial effects of 2,4-diamino-6-quinazolinesulfonamides. J Med Chem.; 27: 1740-3.

Georgopapadakou NH, Walsh TJ. (1996) Antifungal agents: chemotherapeutic targets and immunologic strategies. Antimicrob Agents Chemother.; 40: 279-91.

Greenstein JP, Winitz M. (1961) In Chemistry of Amino Acids. Vol. 2, p 934. Wiley, New York. 
Harrap KR. (1995) Initiatives with platinumand quinazoline-based antitumor molecules. Fourteenth Bruce F. Cain memorial award lecture. Cancer Res.; 55: 2761-8.

Heidelberger C, Danenberg PV, Moran RG. (1983) Fluorinated pyrimidines and their nucleosides. Adv Enzymol.; 54: 57-119.

Hughes LR, Jackman AL, Oldfield J, Smith RC, Burrows KD, Marsham PR, Bishop JAM, Jones TR, O'Connor BM, Calvert AH. (1990) Quinazoline antifolate thymidylate synthase inhibitors: alkyl, substituted alkyl, and aryl substituents in the C2 position. $J$ Med Chem.; 33: 3060-7.

Jackman AL, Farrugia DC, Gibson W, Kimbell R, Harrap KR, Stephens TC, Azab M, Boyle FT. (1995) ZD1694 (Tomudex): a new thymidylate synthase inhibitor with activity in colorectal cancer. Eur J Cancer.; 31A: 1277-82.

Jackman AL, Newell DR, Gibson W, Jordel DI, Taylor GA, Bishop JAM, Hughes LR, Calvert AH. (1991) The biochemical pharmacology of the thymidylate synthase inhibitor, 2-desamino-2-methyl- $N^{10}$-propargyl-5,8-dideaza folic acid (ICI 188583). Biochem Pharmacol.; 42: 1885-95.

Jastreboff M, Kędzierska B, Rode W. (1983) Properties of thymidylate synthase from Ehrlich ascites carcinoma cells. Biochem Pharmacol.; 28: 1251-3.

Jones TR, Smithers MJ, Betteridge RF, Taylor AM, Jackman AL, Calvert AH, Davies LC, Harrap KR. (1986) Quinazoline antifolates inhibiting thymidylate synthase: variation of the amino acid. J Med Chem.; 29: 1114-8.

Jones TR, Thornton TJ, Flinn A, Jackman AL, Newell DR, Calvert AH. (1989) Quinazoline antifolates inhibiting thymidylate synthase: 2-desamino derivatives with enhanced solubility and potency. J Med Chem.; 32: 847-52.

Jones TR, Varney MD, Webber SE, Lewis KK, Marzoni GP, Palmer CL, Kathardekar V, Welsh KM, Webber S, Matthews DA, Appelt K, Smith WW, Janson CA, Villafranca JE, Bacquet RJ, Howland EF, Bartlett CA, Morse CA. (1996) Structure-based design of lipophilic quinazoline inhibitors of thymidylate synthase. J Med Chem.; 39: 904-17.

Kusakiewicz-Dawid A, Bugaj M, Dzik JM, Gołos B, Wińska P, Pawełczak K, Rzeszotarska B, Rode W. (2002) Synthesis and biological activity of $N^{\alpha}$-[4-[N-[(3,4-dihydro-2-methyl-4-oxo6-quinazolinyl)methyl]- $N$-propargylamino]phenylacetyl]-L-glutamic acid. Acta Biochim Polon.; 49: 197-203.

Marsham PR, Jackman AL, Barker AJ, Boyle FT, Pegg SJ, Wardleworth JM, Kimbell R, $\mathrm{O}^{\prime}$ Connor BM, Calvert AH, Hughes LR. (1995) Quinazoline antifolate thymidylate synthase inhibitors: replacement of glutamic acid in the C2-methyl series. J Med Chem.; 38: 994-1004.

Marsham PR, Jackman AL, Oldfield J, Hughes LR, Thornton TJ, Bisset GMF, O'Connor BM, Bishop JAM, Calvert AH. (1990) Quinazoline antifolate thymidylate synthase inhibitors: benzoyl ring modifications in the C2-methyl series. J Med Chem.; 33: 3072-8.

Pendergast W, Dickerson SH, Johnson JV, Dev IK, Ferone R, Duch DS, Smith GK. (1993) Benzoquinazoline inhibitors of thymidylate synthase: enzyme inhibitory activity and cytotoxicity of some sulfonamidobenzoylglutamate and related derivatives. $J \mathrm{Med}$ Chem.; 36: 3464-71.

Rathod PK. (1997) Antimalarial agents directed at thymidylate synthase. $J$ Pharm

Pharmacol.; 49 (Suppl. 2): 704-11.

Rode W, Kulikowski T, Kędzierska B, Jastreboff M, Shugar D. (1984) Inhibition of mammalian tumour thymidylate synthetase by 5-alkylated 2'-deoxyuridine 5'-phosphates. Biochem Pharmacol.; 33: 2699-705.

Rode W, Zieliński Z, Dzik JM, Kulikowski T, Bretner M, Kierdaszuk B, Cieśla J, Shugar D. (1990) Mechanism of inhibition of mammalian tumor and other thymidylate synthases by $\mathrm{N}^{4}$-hydroxy-dCMP, $\mathrm{N}^{4}$-hydroxy-5-fluoro-dCMP, and related analogues. Biochemistry.; 29: 10835-42.

Roeske R. (1963) Preparation of $t$-butyl esters of free amino acids. J Org Chem.; 28: 1251-3. 
Rosowsky A. (1992) Development of new antifolate analogs as anticancer agents. Am J Pharmceut Education.; 56: 453-63.

Synold TW, Willits EM, Barredo JC. (1996) Role of folylpolyglutamate synthetase (FPGS) in antifolate chemotherapy; a biochemical and clinical update. Leukemia Lymphoma.; 21: 9-15.

Takemura Y, Jackman AL. (1997) Folate-based thymidylate synthase inhibitors in cancer chemotherapy. Anti-Cancer Drugs.; 8: 3-16.
Varney MD, Marzoni GP, Palmer CL, Deal JG, Webber S, Welsh KM, Bacquet RJ, Barlett CA, Morse CA, Booth CLJ, Herrmann SM, Howland EF, Ward RW, White J. (1992) Crystal structure-based design and synthesis of benzo[cd]indole-containing inhibitors of thymidylate synthase. J Med Chem.; 35: $663-76$. 